\title{
La erudición en Vera: ¿imitación o plagio?
}

\author{
Carmen Delgado Moral \\ Universidad de Córdoba \\ cdelgadomoral@yahoo.es
}

Fecha de recepción: 20/11/2012, Fecha de publicación: 21/12/2012

\section{Resumen}

El presente artículo destaca la importancia que Fernando de Vera y Mendoza concede a los clásicos grecolatinos en el Panegírico por la poesia (1627); si bien la mayoría de estas citas se encuentran en polianteas, misceláneas y otras obras que funcionan como verdaderas fuentes primarias del Panegírico, su autor evita la objetivación de este uso en el denso aparato erudito que acompaña al texto.

Palabras clave

Fernando de Vera y Mendoza; Panegírico por la poesía; Clásicos grecolatinos; Imitación; Plagio; Erudición

\begin{abstract}
The erudition in Vera: imitation or plagiarism?

This article highlights the importance that Fernando de Vera y Mendoza gives the Greek and Latin authors in the Panegirico por la poesia (1627), although most of these classical quotes are in miscellanies and polianteas, and other works which are the true primary sources for Fernando de Vera who don't quote these sources in his book notes because he doesn't want anybody to know where he got this information from.
\end{abstract}

\section{Key words}

Fernando de Vera y Mendoza; Panegírico por la poesí; Greek and Latin Classics; Imitation; Plagiarism; Erudition 


\section{Procedencia de las fuentes de clásicos grecolatinos}

La portada del Panegírico por la poesía (1627) ostenta un escudo, grabado en cobre, que sirvió a La Barrera como dato incuestionable para la atribución del opúsculo a Fernando de Vera y Mendoza, hijo primogénito del conde de la Roca. Dicho grabado tiene por emblema un águila como símbolo de nobleza, de cuyo pico sale la sentencia "Veritas vincit»; el ave sostiene el escudo de los Vera y se apoya sobre un medallón que representa un campo de flores libadas por una abeja, y en cuyo círculo se lee la explicación de la imagen (suscriptio): «Brevis in volatilibus apis et initium dulcoris habet fructus illius» («Insignificante es la abeja entre los que vuelan y, sin embargo, su fruto es el origen del dulzor»). La imagen de la abeja, que vuelve a aparecer en el período quinto del Panegírico, se ofrece, por un lado, como símbolo de un animal que aporta dulzura con su trabajo y, por otro, como representación del esmero y delicadeza en la realización del mismo, y se identifica con la figura del poeta, cuya creación aporta un edulcorante en los momentos difíciles, de ahí su conexión con la medicina (poesía como «eficacísimo galeno», en palabras de Vera); por otro lado, conforme al ideal humanista, el poeta se muestra como un recreador y reactualizador de doctrinas antiguas que certifican su dignificación, de las que, cual la abeja, va seleccionando y recreando su propia obra. Como vemos, Vera nos ofrece ya desde la portada las claves de su obra.

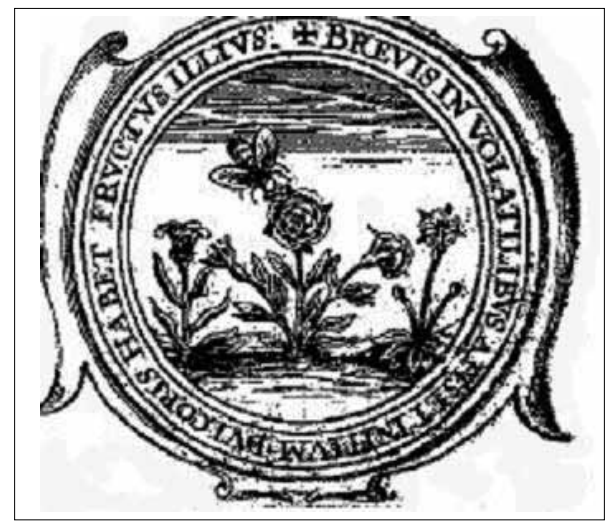

Figura 1.

Detalle de la portada del Panegírico por la poesía.

El símil del poeta y la abeja era frecuente en libros de hieroglífica y emblemática; así, se contiene en el capítulo «Poeticae amoenitas» de la Hieroglyphica de Piero Valeriano, en el que cita a autores latinos como Horacio, quien en el libro IV, 2, de sus Odas (2005: 170) se comparaba a sí mismo con la figura de la abeja: 
Una poderosa aura, Antonio, eleva al cisne Dirceo cuantas veces tiende a las altas regiones de las nubes; yo, al modo y manera de la abeja matina que liba con mucho esfuerzo el agradable tomillo, compongo, modesto, trabajosos poemas junto a los bosques y a las húmedas riberas de Tíbur.

La imagen ya había sido recreada por autores griegos, entre ellos Platón y Plutarco; este último, en Moralia, en el tratado referido a "Cómo debe el joven escuchar la poesía» destacaba la labor de la abeja como ideal de trabajo y sacrificio:

(...) la abeja, por naturaleza, halla en las flores más punzantes y en los espinos más agudos la miel más suave y más útil; los jóvenes, por su parte, al ser educados rectamente en la poesía, aprenderán a extraer de una forma o de otra lo bueno y lo útil, aún de la que es sospechosa de ser mala y absurda (12,32E; 2000: 16-107).

Séneca y Quintiliano, entre otros, también se servirán de dicha imagen, y más tarde lo harán Petrarca y otros humanistas, ya en una evolución hacia una defensa de la imitación que no todos verían con buenos ojos; así, fueron muchos los que para evitar precisamente la similitud que conllevaba la imitatio, y su vinculación con el plagio, iniciaron la defensa de la aemulatio y la creación de un estilo propio. A propósito de esa tenue línea que a veces existió entre la imitación y el plagio, recordemos el prefacio al segundo libro de De elegantiae linguae latinae (1444), en el que Lorenzo Valla acusaba de plagio y robo a los que se apropiaban de sus conocimientos e ideas, y reivindicaba la paternidad de sus escritos:

Hay en efecto quienes han incluido en sus obras algunas de las cosas que yo he dicho, bien porque me las han oído, bien porque se las han oído a mis oyentes (...). De uno de estos, cuando empecé a leer algunos de sus libros por razones de amistad y estando él presente, descubrí algunas investigaciones que eran mías y que no sabía que había perdido; me di cuenta que me las había robado (...). Él lo había tratado de manera negligente y torpe hasta el punto de que podía saberse que lo había tomado de otro y no era fruto de sus propias reflexiones y que lo había oído y no meditado. Me quedé turbado y le digo: «Conozco esa elegancia y alego mi derecho de propiedad, y en cuanto a ti puedo acusarte con la ley de plagio»; pero él, rojo de vergüenza, medio en bromas, medio por educación, me esquivó diciendo que era lícito usar las cosas de los amigos como si fueran propias. «Pero eso, - le digo- es abusar, no usar. Sólo me falta que tú ostentes de manera definitiva el liderazgo de esta investigación en la que yo he trabajado». Entonces él, con más educación si cabe, me replica que sería yo un mal padre si echara de su regazo a los hijos que había engendrado y educado, que él tanto por amistad como por compasión los acogería en su casa y los educaría como si fueran suyos. Desistí de mi enfado comprendiendo que me iría mejor a mí olvidarme de mis bienes que a él recogiendo los bienes olvidados por otros. Porque, ¿quién no ve como algo honesto que aparezcan escritas las investigaciones que yo he realizado y que otros se han apropiado indebidamente, y que es feo para quien lo hace insertarlas en sus obras? (1999: 187-189). 
De un estudio detenido del Panegírico por la poesía se colige que la desbordante erudición del panegirista, que llamó ya la atención incluso del propio Curtius (1976: 760) y que llevó a Alberto Porqueras Mayo a opinar que mejor se adecua al Panegírico el título de la obra de Luis Carrillo y Sotomayor, Libro de la erudición poética (1989: 31), no procede de las fuentes primarias que cita, sino que en un alto porcentaje de casos dicha información nos llega tras el filtro de las polianteas, misceláneas y otras fuentes secundarias - en ocasiones traducciones que interpretan y deturpan los textos originales-; de la lectura de dichas obras, el autor selecciona, reorganiza y en muchos casos incluso parafrasea numerosas ideas para el único objetivo que persigue y justifica en este caso los medios empleados: la dignificación de la poesía en una época, como es el primer tercio del siglo XVII, con la polémica gongorina en todo su apogeo, en la que la erudición, emparentada con la oscuridad, se afianzaba como una marca de distinción y de reconocimiento social en el seno de un estatus nobiliario que cada vez concedía más importancia a la formación humanística. Si el propósito inicial del Panegírico por la poesía pudo ser la realización de un ejercicio escolar, una especie de prueba con un determinado fin (dígase un examen), ello podría justificar tanto la ligereza de la escritura como la copia literal y el plagio sin disimulo que encontramos en numerosas ocasiones; por otro lado, teniendo en cuenta que nos centramos en una época en la que la originalidad no era requisito exigido ni siquiera a los autores consagrados y de prestigio, pues incluso el mismísimo Lope de Vega había sido acusado por Diego de Colmenares de que sus citas procedían de polianteas y otras colecciones de uso común (Porqueras Mayo, 1989: 17) ${ }^{1}$, sería injusto por nuestra parte hacer lo propio con un adolescente de diecisiete años, según la edad que él mismo confiesa en el prólogo.

El Panegírico por la poesía se configura como un ejercicio de retórica, con una notoria influencia de los progymnasmata; como en estos, la materia se distribuye en catorce ejercicios, en este caso denominados períodos, en los que se contienen los elementos esenciales de aquellos, entre los que se cuentan: una exposición sobre el estado de la cuestión del asunto tratado, una narración y amplificación con ejem-

1. Sobre el abuso que de estas prácticas hizo Lope de Vega, y particularmente de la Officina de Ravisio Textor como fuente de erudición, véase Julián González Barrera (2007); y sobre la burla cervantina referida a su "erudición de acarreo» (contenida en el prólogo de la primera parte de El Quijote), el artículo de Pedro Conde Parrado y Javier García Rodríguez (2002). Xabier Tubau (2007) analiza la utilización que hizo Lope de Vega de los libros de lugares comunes, precisamente uno de los reproches que el segoviano Diego de Colmenares difundió en las dos respuestas inmediatas dirigidas contra escritos del Fénix, la primera escrita en 1621, el mismo año de la publicación del "Discurso de la nueva poesía», impreso en La Filomena (1621), y la segunda en 1624, fecha de la respuesta de Lope a la anterior carta de Colmenares, que se publica en $\mathrm{La}$ Cir$c e$, en 1624, y que constituyen uno de los capítulos de la polémica en torno a Góngora y sus seguidores. Quizá dicha enemistad con Lope de Vega fuese la causa de que el nombre de Diego de Colmenares, que además de historiador también escribió algunos poemas, no fuese incluido en el catálogo de poetas que Vera introduce en el período decimotercero del Panegírico por la poesía. 
plos y anécdotas como soporte de la argumentación, una refutación y confirmación, un encomio y un vituperio; de la misma manera, va destinado a un público culto (de ahí que el prólogo se dirija «a los atentos») ${ }^{2}$. Para dichos ejercicios escolares se seleccionaban determinadas lecturas, entre las que no faltaban muchos de los clásicos citados en el Panegírico (Cicerón, Virgilio, Horacio, Plinio, Séneca, etc.), si bien en este también destacan importantes ausencias, como los historiadores Heródoto, Tito Livio ${ }^{3}$, Julio César o Salustio, así como la autoridad de Catulo en la poesía.

La polémica en torno a la imitación ${ }^{4}$ cuenta con importantes defensores en el siglo Xvi (Bembo, Robortello, Fox Morcillo...). Así, el tratado De imitatione seu de formandi styli (1554), de Sebastián Fox Morcillo, recomendaba la imitación como método para el aprendizaje de la escritura, imprescindible, como el propio título manifiesta, en la formación del estilo5. Fox Morcillo, como más tarde lo haría Jáuregui, aconsejaba acudir siempre a las fuentes originales; sin embargo, la propagación de obras de consulta general tales como polianteas, florilegios, cornucopias, etc., repercutió en que las citas a los clásicos latinos, y mucho más a los griegos, pese a la difusión de las traducciones ${ }^{6}$, procediesen en la mayoría de los casos de segunda o tercera mano ${ }^{7}$, resultando muy difícil confirmar la procedencia exacta de la cita. Fue a raíz de la amplia difusión del tratado Poetices Libri Septem (1561) de Julio César Escalígero ${ }^{8}$ cuando la doctrina de la imitación ad-

2. Juan de Guzmán definía los progymnasmata como «exercicios menores que se hacen antes de venir a las cosas mayores» y examinaba su composición en su obra Primera parte de la Rhetorica de Ioan de Guzman...: diuidida en catorze Combites de Oradores: donde se trata el modo que se deue guardar en saber seguir un concepto por sus partes, en qualquiera platica, razonamiento, o sermon, en el genero deliueratiuo, de todo lo qual se pone la theorica y pratica... (1589: 41 y ss.).

3. Tito Livio fue uno de los autores más editados en el siglo XVI (Clavería, 1995: 11; Fernando García, 2010: 58).

4. Ángel García Galiano (1992) ofrece un estudio diacrónico de la imitatio desde sus orígenes clásicos hasta su desprestigio a partir del siglo XVIII.

5. Victoria Pineda (1994) incluye la edición del tratado en su obra La imitación como arte literario en el siglo XVI español. (Con una edición y traducción del diálogo "De imitatio" de Sebastián Fox Morcillo).

6. Hacia 1525 ya se habían impreso la mayoría de las obras griegas importantes; sin embargo, las primeras traducciones de textos clásicos griegos y latinos no destacaron por su perfección y fidelidad al texto (Hernández Miguel, 2008: 99 y 237-238, así como los capítulos dedicados a la transmisión de los clásicos griegos y latinos en el Renacimiento y Barroco españoles).

7. Como señala Lía Schwartz (2008: 21-24), acerca de los métodos de estudio de los clásicos grecolatinos, se reunían frases y sentencias significativas tanto por su valor retórico como por el interés que aportaban para la cultura humanista, recogidos luego en progymnasmata (como la de Antonio Lulio), antologías con fragmentos sobre todo latinos, puesto que el estudio del griego estaba menos extendido. Sobre las antologías de textos griegos, utilizadas a nivel escolar, que ofrecían la traducción latina, véase López Poza (2005); la misma autora (1990) destaca que, conforme avanza la centuria del quinientos se acude «menos a las fuentes y más a las polyanteas», pero será en el siglo XviI cuando dicho recurso se transforme en un «abuso tan ostensible que algunos críticos arremeten con furia contra quienes usan las citas como fin en sí mismo y no como medio». Sobre la enseñanza del griego en el curriculum escolar de las universidades españolas en el siglo Xvi, véase Gil Fernández (2010). 8. Según Gustavo Guerrero (1998: 90), la imitación era para Escalígero un medio, nunca el fin que perseguía la poesía. 
quirió gran popularidad (López Bueno, 2006: 29). En el caso de Vera, las referencias a autores clásicos proceden — como tendremos ocasión de comprobar- de diversas fuentes secundarias de las que va escogiendo citas que se interpolan en el propio texto para obtener la obra que nos presenta en una dispositio sin pretensiones de originalidad. El denso aparato erudito —en su mayoría, insistimos, procedente de fuentes de segunda mano- no tenía otro propósito que el de enaltecer el libro y dignificarlo; a ello hay que añadir la fascinación que producía el hecho de que un joven de diecisiete años estuviese familiarizado con la lectura de autores clásicos, demostrando de esta manera - aunque resultara una ficción-que gozaba de un sólido acervo cultural. El mismo propósito de ostentación debió de perseguir el autor con la dedicatoria de su Panegírico por la poesía al mismísimo conde-duque de Olivares.

Efectivamente, tal y como afirmó Curtius, Fernando de Vera fue un hombre "de mucha lectura», pero del estudio detenido de su obra se deduce que esta no fue tanta como nos quiere transmitir. Fernando de Vera, que pertenecía a una familia bien posicionada económicamente, debió de aprender los usos más rudimentarios de la escritura y el cálculo a partir de los seis años, muy probablemente de la mano de un tutor privado, según era el uso más habitual en las mejores familias, que no querían que sus hijos se mezclaran con los de otros grupos sociales (García Cárcel, 1999: 180-182). Con ocho o nueve años, una vez dominado el uso del castellano, se comenzaba el aprendizaje de la lengua latina. A los diecisiete ańos finalizaba la educación secundaria y se daba inicio a la educación religiosa en conventos, para aquellos que iban a iniciarse en el ejercicio religioso, o a la enseñanza en una de las veinticuatro universidades que ya en el primer cuarto del siglo XvII existían en nuestro país. Por tanto, la realización del Panegírico coincidía con la finalización de la educación secundaria, a la que seguiría una etapa de formación religiosa en Antequera. Vera había aprendido en sus clases de retórica la importancia de la persuasión (movere), imprescindible en un buen orador, cuyo propósito iba dirigido hacia un cambio en la actitud del receptor, producido a través de la estrategia de la emoción o admiración que produce su obra; en el caso que nos ocupa, esta se consigue por la vía de la erudición procedente de un proceso de reelaboración de materiales diversos — ya Francesco Robortello había señalado que la imitación causaba más admiración cuanto mayor era el esfuerzo que suponía. ${ }^{9}$

A pesar de que tras una primera aproximación al Panegírico por la poesía pueda deducirse que su autor manejó un número muy elevado de lecturas, en la mayoría de los casos textos latinos de los que no existía traducción al castellano, lo que nos puede hacer pensar - teniendo en cuenta la corta edad de su autor- que nos encontramos ante un caso extraordinario de erudición o de sobredotación intelectual, lo cierto es que dichas lecturas no fueron tantas como pretende de-

9. Robortello(1548:146):«(...)maioremquídam vi fit imitatio illa; quanto igitur difficilius expri- mi eam posse scimus, tanto magis, si exacta fuerit, admiramur; maioremque capimus voluptatem». 
mostrar. Aunque no ponemos en duda que Vera manejó un número determinado de fuentes latinas, que sin duda conocía por las traducciones de los clásicos tras su estudio de la lengua latina, partimos de la tesis de que para la redacción de su obra manejó diccionarios y obras de consulta generales como las colecciones misceláneas y polianteas, como ya lo hicieran todos sus predecesores (entre los más cercanos a la redacción a la obra, Cascales y Carvallo) y se sirvió especialmente de obras que trataban de la esencia de la materia poética, en una línea próxima a la marcada por la naturaleza del panegírico. Vera cita en dos ocasiones uno de los diccionarios de uso más común de su tiempo: el Dictionarium de Ambrogio da Calepio ${ }^{10}$, a pesar de que era nota común la ocultación de este tipo de obras (Infantes, 1988: 245-257), y es probable que consultara la Officina de Ravisio Textor ${ }^{11}$ y la Polyanthea de Lange. Adelantando una de las conclusiones de nuestro trabajo, podemos afirmar que el Panegírico se presenta, de esta manera, como un ejercicio acorde a la edad de su autor, como una prueba escolar para la que su joven componedor manejó fuentes que, en unos casos, nos muestra en los márgenes del texto y en las que se inspiró e imitó, sin ambición de superación, y, en otros, no confiesa en ningún momento, muchas de las cuales fueron plagiadas en el sentido moderno de la palabra, siendo algo que — subrayando las palabras recogidas anteriormente por Valla - resultaba incluso reprochable en su propio tiempo. Aunque tras el estudio de la obra salta a la luz el indudable talento y sagacidad del adolescente, los métodos empleados por el panegirista revelan una práctica habitual en una época en la que la búsqueda obcecada de esa estética de la erudición, convertida en sinónimo de prestigio por su parangón con la primacía de lo aristocrático que había instalado la autoridad de Góngora, había desembocado en que fueran muchos los escritores los que convirtieran dichas prácticas en un método habitual de trabajo que reducía los costes que sin duda conllevaban el deslumbramiento del lector.

La polémica imitación versus plagio aparece en la Apología de la verdad (1625) de Jáuregui, en la que el sevillano diferencia la imitación del "plagio o imitación mezquina» ${ }^{12}$. Vera, tan exhaustivo a la hora de citar las obras de autores clásicos, no lo es tanto a la hora de citar las verdaderas fuentes que maneja y en las que realmente se vierten los conocimientos de los que hace gala el panegirista. Así, la Genealogía de los dioses paganos se cita en el prólogo, pero no aparece en ninguna de las notas marginales del texto, salvo en una ocasión en la que se refiere a

10. En realidad, aparece citado tres veces a lo largo de la obra, pero en la primera ocasión lo hace fray Juan de Vitoria, para definir el término "panegírico» en su aprobación.

11. Algunos de los personajes y tópicos incluidos en el Panegírico por la poesía se encuentran en la Officina de Ravisio Textor, pero, dada su recurrencia con otras colecciones enciclopédi- cas, no podemos afirmar que se utilizase como fuente. Pedro Ruiz Pérez (1990: 431-440) señala el escaso éxito editorial de la Officina de Ravisio Textor.

12. En palabras Rico García (2001: 99), Jáuregui entiende por plagio la «imitación mezquina, no declarada, a la que considera hurto y no imitación noblemente "procurada»". 
Boccaccio en el período tercero, sin indicar ningún título; la Piazza universale de Garzoni $^{13}$ se cita de una forma muy confusa una sola vez, al final de la obra (en el período decimocuarto), mientras que el Compendio apologético en alabanza de la poesía de Bernardo de Balbuena, obra de la que Vera recogió amplia información, no se cita en ningún momento. Teniendo en cuenta que Vera conoció, consultó y expolió un gran número de episodios, citas y referencias de la obra de Balbuena, el silencio sobre la misma debía de tener una finalidad, y esta pudo ser evitar el descubrimiento por parte del lector de las verdaderas fuentes de su obra.

Si hacemos caso a las palabras de Luis José Velázquez (1754: 169) contenidas en sus Origenes de la poesía castellana, Fernando de Vera es el autor de un «Discurso Apologético en defensa de la Poesía ${ }^{14}$, un título sospechosamente parecido a la obra de Balbuena, razón por la que su autor, en vistas de una futura publicación, pudiera haber sustituido para evitar conexiones que pusiesen en evidencia el débito del Panegírico. Además, el propio fray Juan de Vitoria da la aprobación para la obra que se titula Panegírico en honor de la poesía, de lo que se deduce que, o este desconocía el verdadero título de la obra, o bien que hasta última hora el autor no

13. Porqueras Mayo (1989: 31) ya había señalado la Piazza universale (Venecia, 1585) de Tomaso Garzoni Bagnacavallo (1549-1589) como una de las fuentes primarias de Vera, y también citaba el Compendio apologético en alabanza de la poesía (1604) de Bernardo de Balbuena. Sabemos con certeza que Vera consultó la obra original de Garzoni, en italiano, puesto que la única cita a dicha obra contenida en el Panegírico está referida a Vittoria Colona, que no aparece en la traducción que hizo Cristóbal Suárez de Figueroa en 1615, la Plaza universal de todas las ciencias y artes. Sin embargo, la cita de Vera («plac. del mund.») nos lleva a consultar la traducción castellana, texto que no contiene la mayoría de los episodios que plagia el Panegírico, dato que refleja no solo la personalidad del autor, que probablemente poseía una fantasía de erudición impropia de su corta edad, sino también su propósito de no ser descubierto, algo, por otro lado, muy característico de la ingenuidad adolescente. Sobre la manipulación del texto italiano llevado a cabo por Cristóbal Suárez de Figueroa, véase Arce Menéndez (2008).

14. Rodríguez Ayllón (2010) destaca la importancia de esta obra del malagueño Luis José Velázquez (1722-1772), marqués de Valdeflores, entre los textos iniciadores del estudio de la historia de la literatura española. En una carta dirigida a Agustín Montiano y Luyando, datada en
Mérida, el 15 de abril de 1753, el mismo año en que este publica su Discurso II sobre las tragedias españolas, Luis José Velázquez (1752-1755: 22) afirma tener en su poder el manuscrito de la obra de Vera: "Aquí he recogido algunos Mss. i entre ellos las Poesias d[e] D. Diego d[e] Mendoza (...). De libros impresos tambien he recogido algunos buenos. En el discurso Apologetico en honor $d[e]$ la Poesia compuesto $\mathrm{p}$ [or] D. Fernando Luis $\mathrm{d}[\mathrm{e}]$ Vera, $\mathrm{q}[\mathrm{ue}]$ se imprimio sin nombre $\mathrm{d}[\mathrm{e}]$ Autor, se haze memoria d[e] la tragedia de Dido y Eneas compuesta p[or] D. Guillen de Castro. No tengo presente si habla $V$ [sted] desta tragedia en su primer discurso: si acaso no hablò, la podrà $\mathrm{V}$ [sted] poner en el segundo, citando esta obra como yo la cito, p[or] q[ue] tengo en mi poder el Mss. Original del Discurso». Esta carta de José Luis Velázquez está escrita durante el período que duró su viaje por Extremadura (entre el 1 de diciembre de 1752 y el 10 de septiembre de 1753) como comisionado de la Real Academia de la Historia (de la que era miembro desde 1751). De este viaje Velázquez de Velasco consiguió gran número de manuscritos, actualmente conservados en la Real Academia de la Historia; sin embargo, del manuscrito de la obra de Vera, al que se refiere en la citada epístola dirigida a Montiano y Luyando (a quien había conocido años atrás en la Academia del Buen Gusto madrileña), no tenemos constancia. 
tuvo claro el título completo (solo el término de Panegírico), y, dada la similitud entre las expresiones «en honor», «en alabanza» y «en defensa de», quiso evitar cualquier similitud con la obra de Balbuena y que pusiese al Panegírico en relación con ella. Por otro lado, la obra de Vera no deja de ser un compendio, como el de Balbuena, puesto que — conforme a la definición que aportara Sebastián de Covarrubias - se trata de un discurso que se «ha abreviado de mayor volumen, ciñéndose con lo esencial de la materia ${ }^{15}$, al que se le añade una naturaleza apologética equivalente a la alabanza inherente al panegírico.

Hay muchos ejemplos en los que se advierte claramente la procedencia de la cita de Vera, pero en otras ocasiones no es posible conocer si la cita proviene de Balbuena, de Garzoni o de la Genealogía de Boccaccio, como se puede comprobar en los siguientes ejemplos ${ }^{16}$ :

\begin{tabular}{|c|c|c|}
\hline Panegírico por la poesía & Compendio apologético & Piazza universale \\
\hline $\begin{array}{l}\text { En alabança de la Poesía } \\
\text { han escrito muchos } \\
\text { hombres doctos en todas } \\
\text { facultades. El doctisimo } \\
\text { Budeo en sus anotacio- } \\
\text { nes, sobre los Dijestos. } \\
\text { (1627: } 5 \text { r.) }\end{array}$ & $\begin{array}{l}\text { digo q[ue] la poesia, en } \\
\text { quanto es vna obra y } \\
\text { parto de la imaginaci }{ }^{\sim} \text { o, } \\
\text { es digna de gr ade } \\
\text { cu } \text { eta, de grande } \\
\text { estimació y precio, y } \\
\text { ser alabada de todos y } \\
\text { generalmente lo a sido } \\
\text { de hrobres doctissimos. } \\
\text { Budeo en las anotaciones } \\
\text { sobre el digesto. } \\
\text { (1604: } 120 \mathrm{r} \text { ) }\end{array}$ & $\begin{array}{l}\text { Che merauiglia è che } \\
\text { quel grand'huomo del } \\
\text { Budeo nelle sue Anno- } \\
\text { tationi sopra i Digesti } \\
\text { accumuli tante cose in } \\
\text { lode de'Poeti? } \\
\text { (1605: 927) }\end{array}$ \\
\hline $\begin{array}{l}\text { Y Origenes afirma ser } \\
\text { vna cierta virtud espiri- } \\
\text { tual, que inspira al Poeta } \\
\text { y le rompe el entendi- } \\
\text { miento con su diuina } \\
\text { fuerça (...) (y al margen } \\
\text { la anotación: «Orig. lib. } \\
\text { 1. del periarc.»). } \\
\text { (1627: } 15 \mathrm{r} \text { ) }\end{array}$ & $\begin{array}{l}\text { Origenes en el Pearchon } \\
\text { afirma, que es vna cierta } \\
\text { virtud spiritual que } \\
\text { inspira al Poeta y le llena } \\
\text { el pensamiento de vna } \\
\text { diuina fuerca y vigor } \\
(\ldots) \text {. } \\
(1604: 121 \mathrm{r})\end{array}$ & $\begin{array}{l}\text { Et Origene nel suo libro } \\
\text { del Perarcon, attesta } \\
\text { essere una certa virtù } \\
\text { spirituale, che inspira } \\
\text { il Poeta et gli ri` epie la } \\
\text { mente con la sua divina } \\
\text { forza, e vigore }(. . .) . \\
(1605: 921)\end{array}$ \\
\hline
\end{tabular}

15. Muy ilustrativos resultan los versos del canto primero de La Circe con otros poemas y prosas (1624) de Lope de Vega con los que el Diccionario de autoridades (1726) ejemplificaba la utilización del término: «Que parece imposible su grandeza/ ser reducida a número y compendio».
16. Los ejemplos seleccionados corresponden a las siguientes ediciones: Panegyrico por la poesía (1627); Compendio Apologetico en alabanza de la Poesia, contenido en Grandeza mexicana (1604); y Piazza universale di tutte le professioni del mondo (1605). 


\begin{tabular}{|c|c|c|}
\hline Panegírico por la poesía & Compendio apologético & Piazza universale \\
\hline $\begin{array}{l}\text { y assi lo aprueua S. Basi- } \\
\text { lio en aquella persuasion } \\
\text { que haze a su sobrino: } \\
\text { afirmando que las ficio- } \\
\text { nes de Homero, y los } \\
\text { otros Poetas Griegos son } \\
\text { trompetas que llaman a } \\
\text { la virtud. } \\
(1627: 19 \mathrm{v})\end{array}$ & $\begin{array}{l}\text { Basilio que en su per- } \\
\text { suasoria, ad Nepotem, } \\
\text { afirma q[ue] todas las } \\
\text { ficciones de Homero } \\
\text { y de los otros poetas } \\
\text { Griegos no son otra cosa } \\
\text { que vnos agudisimos } \\
\text { estimulos a la virtud. } \\
\text { (1604: 124r) }\end{array}$ & $\begin{array}{l}\text { valga a lo menos la au- } \\
\text { toridad y credito del grã } \\
\text { Basilio Magno, in quella } \\
\text { sua persuasoria a' nepoti, } \\
\text { non afferma tutti i } \\
\text { figmenti d'Homero, e } \\
\text { de gli altri poeti Greci, } \\
\text { nó esser se non stimoli } \\
\text { pungenti, \& acutissimi } \\
\text { sproni alla virtù? } \\
(1605: 924)\end{array}$ \\
\hline
\end{tabular}

La misma similitud se advierte entre numerosos pasajes contenidos en el Panegírico y una obra hoy prácticamente desconocida, pero en la que se incluyen muchos de los motivos poéticos que encontramos en la mayoría de las poéticas del Siglo de Oro; se trata de la Historia del monte Celia de Nuestra Señora de la Salceda $(1616)^{17}$, de la que podemos afirmar que Vera entresacó una buena parte de los argumentos para la defensa de la poesía, llegando incluso a parafrasear el texto $^{18}$. La obra había aparecido en 1616, un año antes de que Vera iniciase la primera redacción de su Panegírico por la poesía, si bien las licencias están datadas en $1613^{19}$; el libro, obra de fray Pedro González de Mendoza, arzobispo de Granada, sin duda debía de encontrarse ya en las bibliotecas de monasterios

17. Para la historia del monasterio de la Salceda (en la provincia de Guadalajara), lugar de devoción relacionado con unas apariciones marianas que, según tradición popular, acaecieron en el siglo XIII, véase Fernández Madrid y Gómez Lorente (1992). En el Monte Celia, lugar de las supuestas apariciones de la Virgen, fueron excavadas diversas ermitas, y en 1408 se fundó un monasterio de franciscanos, del que llegó a ser prior fray Pedro González de Mendoza (15701639), nombre adoptado por Fernando de Silva y Mendoza, hijo de los príncipes de Éboli y duques de Pastrana, tras su ingreso en la orden franciscana. Pedro González fue el fundador del monasterio de la Salceda, desaparecido prácticamente en su totalidad tras la desamortización de Mendizábal. En 1610 fue nombrado arzobispo de Granada, pasando a la archidiócesis de Zaragoza en 1616, y en 1623 fue elegido obispo de Sigüenza. Fue un hombre de gran cultura, y prueba de ello es su importante biblioteca. Para estas y otras noticias relacionadas con la historia, fundación y descripción del convento, así como otras relacionadas con la biografía del autor que nos ocupa, véase Fernando Marías (1992).

18. Como ya indicó Porqueras Mayo (1989: 35), Vera cita en su Panegírico autoridades que nunca habían sido citados por otros teóricos de la poesía; sin embargo, muchas de estas autoridades se encuentran recogidas en la obra citada del arzobispo de Granada.

19. La licencia real tiene fecha de 16 de agosto de 1613, y las licencias eclesiásticas son de octubre y noviembre. La obra, por tanto, se finalizó al menos tres años antes de su publicación. De esa fecha son también los grabados de los flamencos Francisco Heylan y Jerónimo Strasser (Moreno Garrido, 1976). Vera pudo haber consultado esta obra en Sevilla, donde se conservan varios ejemplares. 
y conventos cuando Vera elaboraba su proyecto. La obra, distribuida en cuatro libros, trata sobre la materia poética en el primer capítulo del libro tercero (titulado «La peregrinación del Alma por el Monte Celia, Descripción de las Cuevas, Hermitas y Casa de Nuestra Señora de la Salceda, con fe de las indulgencias que se ganan»); bajo el pretexto de que el alma, en una peregrinación ascética previa a su presentación ante la Virgen, realizada a través del monte Celia, visitando cuevas y ermitas, capillas y claustros, necesita el aliento que le ofrecen las composiciones poéticas, se interpolan en el texto sonetos, canciones, epigramas, etc., motivo que le sirve al autor para decir «lo q[ue] la Poesia vale»; en su defensa de la poesía, que abarca todo el capítulo referido, el autor realiza una exposición que se inicia con la divinización de la poesía, continuando con su antigüedad y nobleza, la comprensión de todas las ciencias y artes, los efectos admirables de la poesía, la estimación que han recibido los poetas por príncipes y monarcas, la utilidad de la poesía, su ornato y la poesía como símbolo de virtud y de la suavidad de Dios, todo ello ilustrado, como hará Vera, con una síntesis de poética bíblica. Veamos a continuación tres ejemplos que demuestran que Fernando de Vera en ocasiones llegó a plagiar tanto el texto de la Historia del Monte Celia como el aparato erudito contenido en dicha obra:

\begin{tabular}{|l|l|}
\hline \multicolumn{1}{|c|}{ Panegírico por la poesía } & \multicolumn{1}{c|}{ Historia del monte Celia } \\
\hline $\begin{array}{l}\text { y San Atanasio, que el espíritu sucio } \\
\text { que a otros ahoga, es estinguido con los } \\
\text { versos sagrados de los Salmos diuinos } \\
\text { (y al margen aparece la anotación «In } \\
\text { homil. de sem.»). }\end{array}$ & $\begin{array}{l}\text { Dize Sancto Athanasio de los Versos. } O \\
\text { magnam Psalmorum virtutem ¿Spiritus } \\
\text { inmundus suffocans alium, ipse inuisibi- } \\
\text { liter suffocatur. Que es tan admirable, }\end{array}$ \\
& $\begin{array}{l}\text { y peregrina su virtud, que con ellos } \\
\text { los espiritus malignos, que inuisible- } \\
\text { mente estan procurando ahogar a vno, } \\
\end{array}$ \\
& $\begin{array}{l}\text { son ahogados, y vécidos (y al margen: } \\
\text { "Athanasi. in hom. } \mathrm{d}[\mathrm{e}] \text { sem»). } \\
\end{array}$ \\
& $\begin{array}{l}1616: 436) \\
\end{array}$
\end{tabular}




\begin{tabular}{|c|c|}
\hline Panegírico por la poesía & Historia del monte Celia \\
\hline $\begin{array}{l}\text { y Aulo Gelio refiere de Ismenias, que } \\
\text { para la ceatica los aplicaua, y remitia } \\
\text { el dolor, y Plinio (aunque algunos no } \\
\text { le tienen en la opinió que merece su } \\
\text { autoridad, porque escriuió de cosas } \\
\text { naturales, inuestigadas por el, y de no- } \\
\text { sotros no conocidas, propia condicion } \\
\text { humana, creer siempre del otro menos } \\
\text { que de si) cuenta de Vlises el Griego, } \\
\text { que con vnos versos atajaua la sangre } \\
\text { de la herida menos sujeta a esperança. } \\
\text { Y el mismo y Marcelo refieren, que con } \\
\text { versos se sacauan las pajas, o aristas que } \\
\text { caen en los ojos, y lo que se travessaua } \\
\text { en la garganta: y con ellos curaua al Rey } \\
\text { Saul, Dauid (unico medico de su mal) } \\
\text { (nota marginal: «Aul. Gel. lib. } 4 \text {. cap. } 3 \text {. } \\
\text { Lib. } 27 . \text { c. } 11 \text { \& 12. Pined. en la vid. de } \\
\text { San Iuan. } 2 \text { Reg. c. 23»). } \\
\text { (1627: 30r) }\end{array}$ & $\begin{array}{l}\text { dize Aulo Gelio, q[ue] Ismenias curaua } \\
\text { la Ceatica cantãdo versos: Plinio, que } \\
\text { el Griego Vlisses con otros versos, que } \\
\text { sauia, restańaua la sangre de las heridas } \\
\text { mas mortales. El mismo, y Marcello di- } \\
\text { zen, que con versos se sacauã las motas, } \\
\text { o pajas, que caen dentro de los ojos, y } \\
\text { lo que se atrauiessa en la garganta, pues } \\
\text { pudo auer superstición en esto (nota al } \\
\text { margen: «Geli. l. 4. c. 3. Plini lib. } 27 . \\
\text { ca. } 11 . \text { \& 12. Marcel. Pined. en la vida } \\
\text { d[e] S. Iuan. 2. Reg. ca. 23»). } \\
\text { (1616: 415) }\end{array}$ \\
\hline $\begin{array}{l}\text { (...) nuestro primero padre Adan: el } \\
\text { qual el dia (sexto del mundo, primero } \\
\text { suyo) compuso muchos, y Salmos del } \\
\text { Salterio (segun Eusebio, que cita hartos } \\
\text { autores) y especialmente le aplican el } \\
\text { 91. que comienza, Bueno es confessar al } \\
\text { Señor (y en el margen: «Euseb. en su } \\
\text { hist. Cantapetrens. } 1.4 \text {. fol. 332»). }\end{array}$ & $\begin{array}{l}\text { Y el Cantapretense en el Libro quarto, } \\
\text { a este proposito dize lo mismo: y que el } \\
\text { Sexto dia de el mundo, que fuè el Saba- } \\
\text { do, en criando Dios a Adan compuso, y } \\
\text { canto el psalmo nouéta y vno, que co- } \\
\text { miença. Bonum est confiteri Domino (y } \\
\text { al margen: "Cantapetr } 1.4 \text {. fo. } 332 ») \text {. } \\
(1616: 416)\end{array}$ \\
\hline
\end{tabular}

En varios casos Vera cita como fuente la Silva de varia lección de Pedro Mexía, pero comprobamos que dicha cita se encuentra asimismo en la Historia del monte Celia: 


\begin{tabular}{|c|c|c|}
\hline Panegírico por la poesía & Silva de Pedro Mexía & Historia del Monte Celia \\
\hline $\begin{array}{l}\text { Y no fue hazaña menos } \\
\text { suya, despues de entrada } \\
\text { Atenas (assi lo dize Pedro } \\
\text { Mexia) quando hazien- } \\
\text { do ygualar por su suelo } \\
\text { sus edificios y muros, } \\
\text { mandó reseruar desta ira } \\
\text { las casas que auian sido } \\
\text { del Poeta Pindaro, y en } \\
\text { su memoria, las vidas de } \\
\text { todos sus deudos (y al } \\
\text { margen: «3. part. de la } \\
\text { Silu. cap. } 9 ») \text {. } \\
\text { (1627: } 10 \text { r) }\end{array}$ & $\begin{array}{l}\text { Alexandre Magno, que- } \\
\text { riendo combatir y des- } \\
\text { truyr la ciudad de Tebas, } \\
\text { mandó primero que en } \\
\text { la casa y familia de Pín- } \\
\text { daro, poeta vecino della, } \\
\text { no se tocasse por honrra } \\
\text { y respecto de la poesía. } \\
(1989, \text { I: } 62)\end{array}$ & $\begin{array}{l}\text { que solo el Magno } \\
\text { Alexandro nos diera } \\
\text { materia para encarecerlo: } \\
\text { pues yendo lleno de co- } \\
\text { lera, y enojo, a destruyr } \\
\text { a Thebas, se reporto } \\
\text { para mandar primero } \\
\text { a toda la gente de su } \\
\text { exercito, que a la casa de } \\
\text { Pindaro, por ser poeta, } \\
\text { no se tocasse, ni a toda } \\
\text { su familia, por respecto } \\
\text { suyo, se hiciesse dańo, ni } \\
\text { molestia (y al margen: } \\
\text { «Ped. Mexia 3. p. d[e] la } \\
\text { sil. c. } 9 ») \text {. } \\
\text { (1616: } 418)\end{array}$ \\
\hline
\end{tabular}

En otros casos desconocemos si Vera copia de la Historia del monte Celia, de la Piazza de Garzoni o de Balbuena, o si el arzobispo de Granada se inspiraba en alguna de estas obras: 


\begin{tabular}{|c|c|c|c|}
\hline Panegírico & $\begin{array}{c}\text { Historia } \\
\text { del monte Celia }\end{array}$ & Piazza universale & $\begin{array}{l}\text { Compendio } \\
\text { apologético }\end{array}$ \\
\hline $\begin{array}{l}\text { Y Estrabon sien- } \\
\text { te, que la Poesia } \\
\text { contiene en si } \\
\text { todos los Artes } \\
\text { y ciencias del } \\
\text { mundo, y que } \\
\text { nadie era tenido } \\
\text { por sabio, no } \\
\text { siendo Poeta; y } \\
\text { que los antiguos } \\
\text { afirmauan no } \\
\text { ser la Poesia otra } \\
\text { cosa, sino vna } \\
\text { Filosofia princi- } \\
\text { pial, que enseña } \\
\text { las razones y cos- } \\
\text { tumbres de viuir } \\
\text { bien. Y Eraclio } \\
\text { Pontico haze } \\
\text { demostración, } \\
\text { de que la Poesia } \\
\text { está llena de Fi- } \\
\text { losofia natural, } \\
\text { pues descriue los } \\
\text { vientos, las tem- } \\
\text { pestades, los cie- } \\
\text { los, los Planetas, } \\
\text { y todas las cosas } \\
\text { naturales. } \\
\text { (1627: 25r) }\end{array}$ & $\begin{array}{l}\text { No quiero dete- } \\
\text { nerme en probar } \\
\text { sus excelécias } \\
\text { con lo q[ue] dize } \\
\text { Strabon en su } \\
\text { Cronographia, } \\
\text { q[ue] cóprehẽde, } \\
\text { y encierra ẽ si } \\
\text { todas las sciếcias } \\
\text { y las Artes», y al } \\
\text { margen: «Strab. } \\
\text { l. I. Cronog. có- } \\
\text { tra Erathosten». } \\
\text { (1616: 413) }\end{array}$ & $\begin{array}{l}\text { Il dotto Strabone } \\
\text { parládo de’Poeti } \\
\text { nel suo primo } \\
\text { libro della Geo- } \\
\text { grafia, dice che } \\
\text { gli antichi affer- } \\
\text { mauano la poesia } \\
\text { non esser altro, } \\
\text { che vna filosofia } \\
\text { principale, la } \\
\text { qual n'insegna } \\
\text { le ragioni del } \\
\text { viuere, i costumi, } \\
\text { la ciuiltà, \& il } \\
\text { vero reggimento } \\
\text { di noi stessi. Et } \\
\text { Heraclide Ponti- } \\
\text { co dimostra tutta } \\
\text { la poesia essere } \\
\text { ripiena di filoso- } \\
\text { fia naturale, des- } \\
\text { criuendo i venti, } \\
\text { le tempeste, gli } \\
\text { occasi de'pianeti, } \\
\text { il renouar } \\
\text { de'tempi, \& } \\
\text { simili altre cose } \\
\text { naturali (...). } \\
\text { (1605: } 923)\end{array}$ & $\begin{array}{l}\text { y Estrabon. lib. } \\
\text { 1. afirma q[ue] } \\
\text { de la opinió de } \\
\text { los antiguos la } \\
\text { poesia no es otra } \\
\text { cosa que vna } \\
\text { admirable filo- } \\
\text { sofia que enseńa } \\
\text { la razon del viuir } \\
\text { las costumbres } \\
\text { y policia, y } \\
\text { el verdadero } \\
\text { gouierno de las } \\
\text { cosas. Heraclito } \\
\text { Pontico la llama } \\
\text { nata y flor de la } \\
\text { sciencia natural } \\
\text { de que toda esta } \\
\text { quaxada y llena, } \\
\text { descriuiendo } \\
\text { los vientos, las } \\
\text { tempestades, los } \\
\text { cielos (...)». } \\
(1604: 121 v \text { - } \\
122 r \text { ) }\end{array}$ \\
\hline
\end{tabular}

Fernando de Vera realiza una reelaboración de parte de la información recogida en la Historia del monte Celia, y que el arzobispo, a su vez, había recopilado de otras fuentes ${ }^{20}$, y lo combina con conocimientos propios y otros extraídos

20. Francis Cerdan (2008) destaca el hecho de que también los más afamados oradores sacros acudían a obras de consulta general para la elaboración de sus discursos, puesto que incluso las Artes de predicar aconsejaban que se sacasen apuntes de todo tipo de obras. Máxime Chevalier (1976: 59) recuerda la existencia en esta épo- ca de cartapacios de apuntes, algunos de los cuales se han conservado, que los hombres cultos iban entresacando de sus lecturas, y que se limitaban en muchos casos a listados de citas. Según la distinción establecida por este autor (1976: 39), las bibliotecas de obispos y arzobispos se encontraban entre las bibliotecas ricas (con 500 
de las obras ya citadas, conforme a una imitación compuesta (según el término acuñado por Weber) ${ }^{21}$, de forma que el conjunto resultase algo artificial y a la vez original; a tenor de la recomendación de Boccaccio (1983: 832) contenida en el libro XIV de la Genealogia deorum gentilium, referida a la defensa de la oscuridad de la poesía, Vera apuesta por un encubrimiento de «las ficciones», en este caso los argumentos de exaltación poética, «con cuanto artificio puedan» y de este modo las aleja «de los ojos de los torpes». En conclusión, Vera no reconoce sus fuentes primarias, de forma que el lector piense que sus citas proceden de primera mano (clásicos, santos padres, etc.), y en su intención estuvo la obtención del deslumbramiento del lector. Sin embargo, hoy, a la luz de las nuevas tecnologías, su ingenua pretensión es descubierta; no es nuestro propósito, por otro lado, desde la cómoda perspectiva de un lector del siglo xxI, con todos los medios tecnológicos al alcance, inimaginables para el más cultivado de nuestros humanistas del Renacimiento, ceñir la valoración de una obra con respecto al alcance de su imitación.

\section{El canon clásico en el Panegírico por la poesía}

La importancia que reciben los clásicos grecolatinos en el Panegírico por la poesía no es exigua. La obra contiene 151 citas de este tipo, de las cuales el mayor número (104, casi un $69 \%$ del total) corresponde a escritores latinos, y en 62 ocasiones se localiza tanto la obra como el capítulo. Si bien no es comparable con el denso aparato erudito referido a santos padres, doctores de la Iglesia y comentaristas bíblicos, resulta evidente que Vera concibe esta alusión a los clásicos como un apoyo imprescindible en su propósito de erudición; de ahí que la antigüedad se manifieste en todas sus vertientes, desde la geografía y la historiografía hasta la filosofía y la moral, incluyendo la medicina, la biografía, la poesía, la comedia, etc.; esto es, la antigüedad se nos revela como fuente de todo conocimiento.

La renovación y recuperación del mundo clásico grecolatino iniciada en la primera mitad del siglo XIV, entre otros, por el florentino Giovanni Villani en su Crónica Universal, luego continuada por Francesco Petrarca, Nicolás Maquiavelo o Giorgio Vasari, además de inaugurar el rechazo del oscurantismo medieval, desembocaría en una revalorización del hombre y una reivindicación de la dignidad humana. Fueron estudios decimonónicos — como el de Burckhardt, con La cultura del Renacimiento en Italia (1860), o el de Voigt, quien con su clásica obra El

libros o más), acercándose algunas incluso a 2000 volúmenes. Las bibliotecas de letrados y artistas de destacada importancia, entre las que probablemente se encontrara la del conde de la Roca, albergaban unos centenares de libros.

21. El término es empleado por Henri Weber
(1955), quien relaciona precisamente dicha imitación compuesta con la figura de la abeja, que liba de distintas flores para fabricar su propia miel; Lázaro Carreter (1981) lo emplea aplicado a la «Oda a Juan de Grial» de fray Luis de León. 
primer siglo del Humanismo (1859) acuñó el término Humanismo-, los que insistieron en ese resurgimiento del mundo grecolatino que supuso el Renacimiento, que iría acompañado por un redescubrimiento de la historia y la filosofía platónica, frente al aristotelismo medieval reivindicado por la escolástica. En nuestro país, la temprana dignificación del romance con Nebrija, luego continuada en Italia con la Prose della volgar lingua (1525), de Pietro Bembo, o en Francia, con la Défense et illustration de langue française (1549), de Joachim du Bellay, relega el latín a un segundo plano. La batalla al latín se intensifica con Dámaso de Frías y su Diálogo de las lenguas (1582) y, sobre todo, con fray Luis de León, defensor de la lengua castellana incluso en la traducción de los textos sagrados. ${ }^{22}$

Conforme al modelo de discurso oratorio perseguido por Vera en esta obra, el autor más citado entre los clásicos grecolatinos es Cicerón, con dieciséis apariciones, en once de las cuales se menciona tanto la obra como el capítulo. Los títulos que se nombran (por este orden) son: De oratore, Orator, De divinatione, Pro Archia poeta, Oratio pro Sexto Roscio, Tusculanae y De officiis. Su número es, junto con las de Aristóteles, superior al del resto de autores grecolatinos contenidos en el Panegírico y las citas se refieren especialmente a la utilidad de la poesía y origen divino; con respecto a la divinización del poeta o teoría del furor, las ideas poéticas de Cicerón se ponen en correspondencia con las de Demócrito, que es citado en una única ocasión en el período primero de la obra ${ }^{23}$. Resulta difícil averiguar si dichas citas las conocía el autor por el estudio y traducción de los textos latinos que había manejado durante sus estudios, o bien proceden de polianteas y otras obras de consulta general; lo que sí resulta evidente es que obras como la Genealogía de los dioses paganos de Boccaccio, o el Compendio apologético de Bernardo de Balbuena, contenían muchas de las referencias de las que indudablemente se sirvió nuestro autor. La Polyanthea de Joseph Lange ${ }^{24}$ contiene algunas de las citas más conocidas de Cicerón; así, en los temas referidos al orador y la elocuencia, Lange (1617: 1007-1008) recoge diversos pasajes de las obras retóricas de Cicerón, especialmente los referidos a la formación del orador. Pese a que los materiales de los que hace acopio Vera proceden en su mayor parte de este tipo de colecciones enciclopédicas, así como composiciones misceláneas y otras

22. García Cárcel (1999: 142) señala que, pese a que existía la consciencia del latín como lengua de carácter universal, los epistolarios de los jesuitas demuestran que su uso en los colegios de la compañía era lamentable.

23. Luis Gil (1967: 36) ha estudiado la afinidad existente entre algunos pasajes de los tratados De oratore y Pro Archia de Cicerón y los fragmentos 17 y 18 de Demócrito.

24. El bibliófilo Lorenzo Ramírez de Prado, al que Vera elogia en el catálogo de autores contenido en el período decimotercero y al que considera digno "de alabanza e imitación", poseía un ejemplar de la Polyanthea de Lange en su magnífica biblioteca madrileña, que Vera pudo utilizar, dada la amistad que le unía, en alguno de sus viajes que hizo a la corte en compañía de su padre. Por otro lado, la amplia difusión de estas obras lleva a Víctor Infantes (1988: 250) a deducir que debía de tratarse de libros de obligada consulta en las universidades. 
obras de consulta general, Vera integra los tres factores que el maestro de la oratoria concebía imprescindibles en un perfecto orador: disposición natural, cultura profunda en todas las disciplinas (Filosofía, Historia, Derecho...) y conocimientos de la técnica del discurso, demostrando una asimilación del procedimiento oratorio que el modelo de la elocuencia latina formulara en sus tratados Oratory De oratore. En el plano de la inventio, los argumentos que prueban su discurso resultan adecuados para el objetivo que persigue, y son similares a los utilizados por otros tratados de preceptiva anteriores, como el Compendio apologético (1604) de Bernardo de Balbuena o el Cisne de Apolo (1602) de Alfonso de Carvallo, así como misceláneas como la Silva de varia lección (1540) de Pedro Mexía. La disposición de dichos argumentos también continúa la línea de otros tratados de preceptiva: primero el elogio del arte poético, la alabanza que personajes ilustres de la antigüedad han realizado del mismo (incluyendo un repertorio de anécdotas), antigüedad del arte poético, comparación con otras artes, etc. En el plano de la elocución, Vera pretende deslumbrar con un aparato crítico que demuestra, aunque de forma ficticia, como ya hemos señalado, una desbordante erudición.

Ya desde el Renacimiento italiano, Cicerón era considerado como el prosista más excepcional de todos los tiempos y su calidad literaria resultaba indiscutible. El siglo Xv había inaugurado, especialmente con la figura de Petrarca, lo que Étienne Gilson (1974: 121) denominó la "aetas ciceroniana» ${ }^{25}$, iniciándose un verdadero culto hacia la figura de Cicerón, solo ensombrecida por las polémicas surgidas a raíz de la publicación del tratado De imitatione (h. 1413-1417) del humanista Gasperino Barzizza, quien se pronuncia a favor de la imitación compuesta $^{26}$. Ángel García Galiano recuerda que durante los siglos xvi y principios del XviI se publicaron en Europa un gran número de manuales de elocución ciceroniana, como el del valenciano Pedro Juan Núnez, titulado Epitheta M. T. Ciceronis collecta (1570), quien, partidario de una imitación simple (como mantenía

25. Destaca Highet (1978: 62) que el estilo de Cicerón era «el de la Iglesia, el de las universidades, el de los jesuitas, el de las cancillerías de despachos extranjeros» y el de la ortodoxia en general, frente al de Tácito, que se asociaba a lo heterodoxo «y aun con el libertinaje».

26. Sobre la polémica surgida en torno a la obra y estilo de Cicerón entre ciceronianos y anticiceronianos desde el siglo XIV hasta finales del XVI, véase la introducción de Manuel Mañas Núñez (2009) a El ciceroniano (o sobre el mejor estilo), de Erasmo de Rotterdam. El planteamiento del debate giraba en torno a la imitación exclusiva de Cicerón como modelo supremo de elegancia (imitación simple, defendida por Pietro Bembo, Paolo Cortese y Cristophe de Longueil, entre otros) y la imitación alternativa de otros modelos (imitación compuesta, propuesta por Erasmo, Poliziano y el Brocense). En Espańa, el Brocense, siguiendo a Erasmo, se decantará por una imitación compuesta en la que, admitiendo la preeminencia del estilo del orador latino, también admitirá las estructuras lingüísticas de otros modelos; sobre este particular, véase la obra de Juan María Núñez González (1993), y el artículo de Jorge Fernández López (1999), en el que recoge la expresión latina del humanista y profesor de retórica Juan Lorenzo Palminero, de su obra De vera et facili Ciceronis imitatione, dedicada «a adiestrar a sus lectores en la escritura de una prosa latina lo más cercana posible a la del modelo por excelencia: Cicerón». 
Paolo Cortese, entre otros), propone al escritor romano como único modelo de elegancia y perfección en el estilo y, por tanto, de imitación (García Galiano, 2010). Juan $M^{a}$ Núñez (1993: 123) ha señalado la importancia de la labor de los jesuitas en la pervivencia de las imitaciones de Cicerón, con obras como la de Bartolomé Bravo (De arte oratoria, ac de eiusdem exercendae ratione Tullianaque imitatione, de 1596), que se prolongan hasta entrado el siglo XvII, como es el ejemplo de las Tullianae quaestiones de instauranda Ciceronis imitatione (1616), de Andreas Scottus. Los discursos retóricos de Cicerón se concebían como un ejemplo de perfección para la técnica del discurso, y Vera, que lo toma como modelo de oratoria, pretende acercarse a él con su discurso, si bien su alegato carece de novedad tanto por la elección de un asunto con una dilatada trayectoria como por la aportación de argumentos para la defensa, siendo redundantes tanto los elogios como las anécdotas, las objeciones y, por supuesto, las fuentes.

En segundo lugar, el clásico más citado en el Panegírico por la poesía es Virgilio, con quince apariciones, en seis de las cuales se cita su Eneida ${ }^{27}$, y solo en una ocasión se nombran sus obras menores: las Églogas y las Geórgicas. La mayoría de las referencias aparecen localizadas, si bien no encontramos ningún caso de cita textual. En más de una ocasión la figura de Virgilio se muestra como una autoridad desde tiempos de Marcial, apenas ochenta ańos después de su muerte; a propósito de este, Vera apunta en el período segundo que «fue muy querido del emperador Eliovero, el cual le llamaba su Virgilio», con lo cual queda demostrada la estimación que el poeta merecía para sus sucesores. Mas cabe destacar que dicha fama y consideración se debía especialmente a su obra épica, de ahí que Vera la cite con especial énfasis, que no su producción lírica; así, el propio Marcial se lamentaría del escaso provecho que reciben los poetas líricos, frente a los poetas épicos (como Virgilio), en el epigrama que lleva por título "Los epigramas tratan de asuntos serios, no de tonterías» (IV, 49), en el que defiende el valor del epigrama frente a la ampulosidad de la poesía épica. También en el período undécimo Vera cita una vez más a este autor como autoridad al referirse a «los Virgilios y Horacios de la poesía», convirtiendo a estos en los autores por antonomasia (auctoritas), y elevándolos a la categoría de patrón o canon, lo cual permite la canonización del género y su «autorización».

Tácito es mencionado en catorce ocasiones, en diez de las cuales se cita la obra y el capítulo; es muy probable que Fernando de Vera consultase sus obras ${ }^{28}$, pues-

27. Existe una temprana traducción del segundo libro de la Eneida (Siguese el segundo libro de las Eneydas) por Francisco de las Natas, publicada en Burgos, en 1526, a la que le sigue una traducción completa titulada Los doze libros de la Eneida (Toledo, 1555). La valoración de autores establecida por Vera en el Panegírico por la poesía no coincide con los intereses de los editores españoles de la época, centrados en un negocio que durante años despreció a autores como Virgilio, Horacio o Quintiliano, entre otros; sobre este particular, véase Clavería (1995).

28. Las obras que Vera menciona son los Ana- 
to que Tácito, «el gran maestro de los políticos», como lo denominara Francisco Morovelli de Puebla, se había convertido ya en el Renacimiento en una autoridad indiscutible y alcanzaría durante el siglo xvir su máximo momento de autoridad $^{29}$; editado por Justo Lipsio desde 1574, su relevancia como escritor político e historiador se convirtió en fuente de inspiración de numerosas obras, como los Comentarios políticos a los Anales de Cayo Vero Cornelio Tácito ${ }^{30}$ de Juan Alfonso de Lancina, De Constantia (1584) de Justo Lipsio o El Embajador (1620) de Juan Antonio de Vera y Zúníga. Según Elliott (1998: 55), el atractivo que ofrecía Tácito a los hombres del siglo xvII era el que "ofrecía unas lecciones históricas de gobierno aplicables tanto a su propia época como a la antigua Roma», de ahí que el propio conde-duque lo tuviese como uno de sus autores predilectos de la antigüedad romana. A ello podemos añadir que, para los escritores del Barroco, Tácito representaba el paradigma de lo aristocrático, de una nobleza de sangre que venía predeterminada por el nacimiento y que se evidenciaba en la pertenencia a un grupo social privilegiado, singularizado en un código de conducta reflejo de una educación basada en el estudio de los clásicos, y condicionada por una determinada ideología de carácter autoritario, definida por los teóricos del iusnaturalismo. ${ }^{31}$

Las traducciones al español de los Anales realizadas por Manuel Sueyro (Las obras de C. Cornelio Tacito, Amberes, 1613), Baltasar Álamos de Barrientos (Tácito español, Madrid, 1614) y Antonio de Herrera y Tordesillas (Los cinco primeros libros de los annales de Cornelio Tacito, Madrid, 1615), así como los sucesivos trabajos de Justo Lipsio, hicieron de él una de las autoridades más apreciadas y discutidas en la época de Fernando de Vera; ya su padre le había concedido una especial importancia en El Embajador, obra en la que encontramos un total de once citas referidas a este historiador. Dada la cercanía entre el conde de la Roca y Olivares, y sabido el gusto que ambos sentían hacia las obras de Tácito, no es de extrañar que este se convierta en uno de los autores antiguos más citados. Por otra parte,

les (sobre todo), las Historias y Costumbres de los germanos. El hecho de que Vera no cite en ningún momento el Diálogo de los oradores, una obra muy próxima al modelo ciceroniano de defensa de la oratoria, puede deberse a que esta no había sido incluida en las traducciones de Sueyro y Álamos de Barrientos, por considerarse falsa su atribución.

29. Beatriz Antón Martínez (1992: 107-155) señala tres vías importantes de divulgación del tacitismo: una italiana (con estudiosos como Alciato, Botero, Boccalini, Ammirato, Guicciardini y Malvezzi), una vía francesa (con Bodini, Budé y Mureto, entre otros, que contribuyeron en gran medida en la recepción del tacitismo en nuestro país) y una vía flamenca o lipsiana (que debe su denominación al importante papel protagonizado por el humanista Justo Lipsio en el proceso de construcción del tacitismo); por último, cabe citar una cuarta vía alemana, mucho más secundaria.

30. El manuscrito original, conservado en la Biblioteca Nacional, data de 1601, y se utilizó para la primera edición de la obra realizada por Melchor Álvarez en Madrid, en el ańo 1687.

31. Sobre la relación de Tácito con este sentimiento aristocrático, y su desprecio hacia todo lo vulgar, véase Herrero Llorente (1960). En su "Discvrso para inteligencia de los Aforismos, vso, y provecho dellos», Álamos de Barrientos (1614: s/f) se refería a Tácito como un autor "esclarecido y escuro». 
la mayoría de las citas contenidas en el Panegírico nos ofrecen noticias literarias relacionadas con la historia de Roma; se trata, especialmente, de una recopilación de datos históricos concretos que le sirven a Vera para el objetivo último de su Panegírico, y que no es otro que la reivindicación y alabanza del arte poético.

El siguiente autor en relación al número de referencias es Homero, con un total de doce apariciones a lo largo del Panegírico. A pesar de ello, no podemos concluir que se trate de un autor que ostente un valor importante en la obra de Vera, puesto que la mayoría de las referencias que hacen alusión a él carecen de localización y tan solo encontramos dos casos de citas textuales (en castellano), cuya procedencia pudiera estar en alguna poliantea, como la de Lange, tal y como se puede apreciar en el siguiente ejemplo:

\begin{tabular}{|l|l|}
\hline \multicolumn{1}{|c|}{ Panegírico por la poesía } & \multicolumn{1}{c|}{ Poliantea de Lange } \\
\hline $\begin{array}{l}\text { Honesto es oyr Poetas (dixo Homero) } \\
\text { pero tales qual es este (hablando de vno) } \\
\text { semejante a los Dioses en su voz (al mar- } \\
\text { gen: «Homer. In Vbix»). }\end{array}$ & $\begin{array}{l}\text { «Homer. in Odyss.: (...) Honestum } \\
\text { est audire poetam:/ Talem, qualis hic } \\
\text { (1627: diis similis in voce». } \\
\end{array}$ \\
\hline
\end{tabular}

Si exceptuamos dos ocasiones en las que Vera cita la Odisea (sin localización de canto) $)^{32}$ y una en la que hace una referencia a la Ilíada, el resto de citas homéricas se ciñen a la figura de Homero como autoridad indiscutible ya desde los tiempos de la antigüedad grecolatina. Si seguimos manteniendo la autoridad de Homero como poeta cumbre de la literatura griega, así como Cicerón (en la prosa) y Virgilio (en poesía) en la literatura latina, nos sorprende el que sea Tácito el autor más citado, por encima de los anteriores, lo cual explicamos por las razones ya aludidas anteriormente.

El resurgimiento del poeta Horacio en el Renacimiento (Lida de Malkiel, 1975: 259) queda aquí de manifiesto en las doce referencias que Vera hace de este autor a lo largo del Panegírico, de las cuales en cinco ocasiones se cita el Arte poética, especialmente para recoger algunas de sus ideas poéticas que con más insistencia aprovecharon los preceptistas de los siglos XVI y XVII, como la del docere delectare y la clasificación de la poesía en cuatro estilos poéticos (épico, trágico, cómico y lírico). Junto a las citas de la Epistula ad Pisones, también encontramos una referencia a las Odas, de las cuales se extraen algunos versos traducidos al castellano; las demás aparecen sin localización, y en dos ocasiones se nombra a Horacio como autoridad en referencia a su estilo poético.

32. Parece que Vera cita la obra de Homero a través de la traducción cuyo título es De la Ulyxea de Homero. XIII libros, traducidos de Griego en Romance Castellano por Gonçalo Perez, cuya primera edición apareció en Amberes (en casa de Juan Stelsio), 1550. 
Aristóteles y Platón destacan por ser autoridades menos citadas (con diez apariciones el primero y seis el segundo), mas el peso de ambos, sobre todo de Platón, es incuestionable en el Panegírico. Frente a la autoridad indiscutible que Aristóteles ejerció sobre la escolástica del siglo XIII, a partir de la labor de Petrarca y de las traducciones de Leonardo Bruni y de Pier Cándido Decembrio, se potencia la lectura y difusión de la obra de Platón ${ }^{33}$ y se prepara el camino para la consolidación del neoplatonismo en Florencia con Marsilio Ficino y Pico della Mirandola, especialmente a través de la labor realizada por la Academia platónica fundada en 1459 por Cosme de Médicis. Desde Florencia se irradia a los focos humanistas occidentales, que revalorizan la figura de Platón, cuyas principales ideas poéticas (como la del furor divino), así como su consciencia de la belleza del arte poético, lo elevarán a la cumbre de la admiración de los neoplatónicos como Marsilio Ficino; de ahí que Vera cite a este último en relación a las ideas de la divinización de la poesía que Platón vierte en varios de sus diálogos, como Leyes y Fedro, en un intento de conciliación del pensamiento pagano con la doctrina cristiana, muy al estilo de la labor ya iniciada por los primeros humanistas. De Platón se aprovechan solamente los consejos "amables» en relación con la poesía, tales como el de "no enemistar a los poetas", "codiciar su amistad"; sin embargo, en relación al mayor tópico del platonismo, el destierro de los poetas de la república ideal de Platón ${ }^{34}$, no se cita su autoridad directamente. Junto a la teoría de los neoplatónicos, también se ponen en relación con Platón la teoría de los pitagóricos referente a la vinculación de la poesía con la música, así como la relación de esta con los estudios matemáticos.

En cuanto a Aristóteles, sus citas se refieren especialmente a aspectos filosóficos (sobre todo las que aluden a tratados como Etica Nicomáquea, Física, Sobre el alma o Metafísica); sin embargo, no se cita en ninguna ocasión la Poética, cuya primera traducción al castellano se realiza en 1626. De gran utilidad es para Vera la clasificación que realizó Aristóteles de los saberes en teóricos, prácticos y poéticos, que él tomó como base para su clasificación de las ciencias, así como otras ideas filosóficas reactualizadas por santo Tomás. Muchas de las citas de Aristóteles se encuentran en polianteas y misceláneas, y se incluyen en los tratados de preceptiva del Siglo de Oro, lo cual demuestra la pervivencia del aristotelismo en la enseńanza en los siglos XVI y XVII, tras la labor desarrollada por Pietro Pomponazzi en la Universidad de Padua entre 1487 y $1509^{35}$, presente ya en

33. Vid. Schmitt (1976). El autor señala al humanista alemán Paulus Niavis (h. 1460-1514) como el primer profesor que enseña a Platón a nivel universitario.

34. Sobre el cambio de mentalidad acerca de la expulsión platónica del artista y el poeta imitativo, que se inició en el Renacimiento italiano (especialmente en Florencia), y que se evidencia especialmente en Pico della Mirandola y otros humanistas italianos, véase Eugenio Trías (1997). 35. Vid. Jacques Roger (1976 : 218). Michel Reulos (1976: 152) destaca la ausencia de conflictos entre Aristóteles y Platón en la enseñanza de los colegios del siglo xvi. Schmitt, en su clásico estudio Aristotle and the Renaissance (1983), reeditado en 2004 por la Universidad de León, 
los programas universitarios de dicha centuria. La obra filosófica del Estagirita contó con mayor interés por parte del público; prueba de ello es su temprana traducción titulada La philosophia moral de Aristotel: es a saber Ethicas, Polithicas y Economicas: en Romance (Zaragoza, 1509), a la que seguiría el Compendio de toda la Philosophia natural de Aristoteles: traduzido en metro castellano... (Estella, 1547), manifestación de la vigencia de la corriente naturalista en filosofía contenida en la Física.

De las seis menciones que podemos encontrar relativas a Plinio el Viejo, la mitad se refieren a noticias literarias relacionadas con hechos concretos de la antigüedad; Vera nunca cita la Historia natural y no reproduce ninguna cita textual, posiblemente por el descrédito que esta obra sufrió en el siglo XVII, precisamente por el hecho de haber sido expoliada con destino a obras de procedencia miscelánea; el propio Vera (1627: $30 r)$ se hace eco de este desprestigio:

y Plinio (aunque algunos no le tienen en la opinió que merece su autoridad, porque escriuió de cosas naturales, inuestigadas por el, y de nosotros no conocidas, propia condicion humana, creer siempre del otro menos que de si).

Podemos afirmar que las referencias a este autor no están extraídas directamente de su producción, puesto que son citas frecuentes en misceláneas como la Silva de Pedro Mexía. A pesar de que todas ellas están localizadas con el número del libro y el capítulo, en la mayoría de los casos la localización que aporta de sus citas es incorrecta, ya que casi todas se centran en el libro séptimo de la Historia natural, cuyas noticias acerca de los honores concedidos a los poetas por parte de reyes y emperadores fueron muy aprovechadas en libros de varia erudición; así, dichas noticias se recogen en la obra de Pedro Mexía, a la que Vera pone en relación con Plinio en la primera ocasión en la que se exalta la poesía como arte digno de la mayor veneración ${ }^{36}$, localizando en nota al margen primero la miscelánea de Mexía y a continuación la autoridad de Plinio, lo cual nos indica ya la procedencia de la cita.

En cuanto a Ovidio, son escasas las referencias a su obra (solamente se cita en cinco ocasiones), a pesar de que es el autor latino que mayor número de traducciones al castellano tuvo en los siglos XVI y XVII ${ }^{37}$. No encontramos ninguna

señalaba que la recepción de Aristóteles en España se prolonga hasta 1640 .

36. La anécdota protagonizada por Alejando Magno, el cual asignó a los escritos de Homero el cofre de los tesoros arrebatado al rey Darío, y que Fernando de Vera incluye en el período segundo del Panegírico, es uno de los episodios más repetido en las defensas de la poesía.

37. José Simón Díaz (1980) señala un total de doce traducciones al castellano de la obra de Ovidio, autor al que le siguen Cicerón, Séneca y Virgilio, con nueve traducciones. Sobre la historia de la transmisión manuscrita e impresa de la obra amatoria de Ovidio (Amores, Ars amandi y Remedia amoris) en España, véase Arcaz Pozo (1992: 1-79). Una de las traducciones españolas del Ars amandi se debe precisamente a fray Melchor de la Serna, probablemente uno de los 
cita mitológica contenida en las Metamorfosis; de él se aprovechan especialmente algunas alusiones referentes a la poesía del Ars Amatoria ${ }^{38}$ y a la teoría de la inspiración poética contenida en Fastos (obra que no cita). La última cita textual con la que se cierra el Panegírico por la poesía procede precisamente de este autor, concretamente de su obra Amores; pero, como podemos comprobar, es probable que la cita no proceda -una vez más- de primera mano, sino que está recogida en la Polyanthea de Lange, precisamente bajo el título de "elegía última», tal y como declara Vera - aunque sin mencionar ningún tipo de fuente- en su última nota; por otro lado, la cita pudo haber sido seleccionada por Vera por su evocación de unos versos de Cicerón contenidos en De officiis.

Lucano también aparece en cinco ocasiones, pero solo en una ocasión (en el período decimocuarto) se cita una de sus obras, la Farsalia, obra en la que colaboró su mujer, Pola Argentaria, dato que se encuentra en Lucano traduzido de verso latino en prosa castellana por Martin Lasso de Oropesa (1535) ${ }^{39}$. En dos ocasiones se relaciona con Nerón, refiriéndose a la rivalidad que este mantenía con él acerca de sus versos y al episodio de su muerte, y se cita como fuente los Anales de Tácito. También se alude como autoridad, en relación con Marsilio Ficino, para hablar del furor poético, aludiendo a unos versos contenidos en la Farsalia, aunque no la cita. Por último, en el catálogo de poetas contenido en el período decimotercero, del marqués del Carpio y don Luis de Guzmán y Haro se dice que «son el Séneca y Lucano de Córdoba».

Estrabón y Séneca aparecen en cuatro ocasiones. Del primero se localizan las citas, pero sin indicar el título del libro, entendiéndose que se refiere a su obra principal, la Geografía ${ }^{40}$. De Séneca se menciona únicamente su tratado De $i r a^{41}$. El resto de autores mencionados aparecen en una o dos ocasiones, como se puede apreciar en el cuadro que ofrecemos a continuación, lo cual demuestra el deslinde que realiza Vera entre clásico y canon, si bien los límites - como señala Eric Sullà (1998: 20)— continúan siendo confusos. Únicamente quería-

poetas que Vera cita en el período decimotercero del Panegírico por la poesía. Rudolph Schevill destaca la influencia de Ovidio en el Renacimiento español en su obra Ovid and the Renascence in Spain (1913).

38. Sobre la traducción que Diego Hurtado de Mendoza realizó de la elegía octava del libro I de Amores, véase Arcaz Pozo (1994); y sobre la adaptación realizada por dicho autor en su «Sátira de una alcahueta», véase Cacho Casal (2007: 71-77).

39. El autor de la primera traducción al castellano de la Farsalia, Martín Laso de Oropesa, había sido acusado de luteranismo, y más tarde de alumbrado. Juan de Jáuregui compuso una versión de la Farsalia, en octavas reales, que fue impresa póstumamente en 1684. Víctor-José Herrero Llorente ha escrito diversos artículos sobre la influencia de Lucano en Espańa, además de su tesis doctoral (inédita) Lucano en España (Universidad Complutense de Madrid, 1957); vid. Herrero Llorente (1959), así como su introducción a La Farsalia, especialmente los epígrafes «Lucano en España» y «Las traducciones españolas de la Farsalia» (1996: XLI-LII).

40. Sobre la contribución de Estrabón en la historiografía española, véase Álvarez MartíAguilar (1999).

41. Sobre la recepción de Séneca en nuestro país, véase la obra de Karl Alfred Blüher (1983). 
mos destacar, aunque solamente aparezca en una ocasión, la figura de Plinio el Joven, del que se cita al final de la obra su Panegírico a Trajano, que había sido traducido al castellano por Francisco de la Barreda en 1622. Con esta referencia se cierra el discurso oratorio que Vera había comenzado en su período primero con la autoridad de Cicerón como maestro.

\section{Citas de autoridad: clásicos grecolatinos}

A continuación se detallan por períodos las citas de autores grecolatinos contenidas en el Panegírico por la poesía. Los preliminares carecen de citas de este tipo. Los apartados a, b, c, corresponden respectivamente a citas en el texto (a), citas al margen (b) y citan en el texto y al margen (c).

\begin{tabular}{|c|c|c|c|c|c|c|c|c|c|c|c|c|c|c|c|}
\hline Autor & & P1 & P2 & P3 & P4 & P5 & P6 & P7 & P8 & P9 & $\begin{array}{c}\mathrm{P} \\
10\end{array}$ & $\begin{array}{c}\mathrm{P} \\
11\end{array}$ & $\begin{array}{c}\mathrm{P} \\
13\end{array}$ & $\begin{array}{c}\mathrm{P} \\
14\end{array}$ & $\begin{array}{l}\text { Total } \\
\text { citas }\end{array}$ \\
\hline \multirow{3}{*}{ Cicerón } & $\mathrm{a}$ & & & & & & 1 & & & & & & & 1 & \multirow{3}{*}{16} \\
\hline & $\mathrm{b}$ & 1 & 2 & & & & & & & & & 1 & & & \\
\hline & $\mathrm{c}$ & 2 & 1 & 2 & & 2 & & 1 & & 1 & & 1 & & & \\
\hline \multirow{3}{*}{ Virgilio } & $\mathrm{a}$ & & 2 & & & & & 1 & & & 3 & & 2 & 1 & \multirow{3}{*}{15} \\
\hline & $\mathrm{b}$ & & & & & 3 & & & & & & & & & \\
\hline & c & & & & & 1 & & & 2 & & & & & & \\
\hline \multirow{3}{*}{ Tácito } & $\mathrm{a}$ & & & & & 2 & & & & & & & & 1 & \multirow{3}{*}{14} \\
\hline & $\mathrm{b}$ & & 1 & & & & & 1 & & & 2 & & & & \\
\hline & $\mathrm{c}$ & & & 1 & & & 1 & 2 & & 1 & 2 & & & & \\
\hline \multirow{3}{*}{ Homero } & $\mathrm{a}$ & & 3 & 1 & & 2 & 1 & & 1 & & 1 & & & 1 & \multirow{3}{*}{12} \\
\hline & $\mathrm{b}$ & & & & & & & & & & & & & & \\
\hline & c & 1 & & 1 & & & & & & & & & & & \\
\hline \multirow{3}{*}{ Horacio } & $\mathrm{a}$ & & & & & & & & 2 & & 1 & 1 & & & \multirow{3}{*}{12} \\
\hline & $\mathrm{b}$ & & & & & 4 & & & & & & 1 & & & \\
\hline & c & & & 1 & & & & & 1 & & & 1 & & & \\
\hline \multirow{3}{*}{ Aristóteles } & $\mathrm{a}$ & & & 1 & & & 2 & 1 & & & & & & & \multirow{3}{*}{10} \\
\hline & $\mathrm{b}$ & & & & 1 & & 1 & & & & & & & & \\
\hline & $\mathrm{c}$ & & & & 2 & & 2 & & & & & & & & \\
\hline
\end{tabular}




\begin{tabular}{|c|c|c|c|c|c|c|c|c|c|c|c|c|c|c|c|}
\hline Autor & & P1 & P2 & P3 & P4 & P5 & P6 & P7 & P8 & P9 & $\begin{array}{c}P \\
10\end{array}$ & $\begin{array}{c}P \\
11\end{array}$ & $\begin{array}{c}P \\
13\end{array}$ & $\begin{array}{c}P \\
14\end{array}$ & $\begin{array}{l}\text { Total } \\
\text { citas }\end{array}$ \\
\hline \multirow{3}{*}{ Plinio } & $\mathrm{a}$ & & & & & & & & & & & & & & \multirow{3}{*}{6} \\
\hline & b & & 2 & & & & & & 1 & & & & & & \\
\hline & c & & 1 & & & & & 1 & & 1 & & & & & \\
\hline \multirow{3}{*}{ Platón } & $a$ & 1 & & 1 & & & & & & & & & & & \multirow{3}{*}{6} \\
\hline & b & & & 1 & & & & & & & & & & & \\
\hline & c & & 1 & 1 & & & & & 1 & & & & & & \\
\hline \multirow{3}{*}{ Ovidio } & a & 1 & & 1 & & & & & & & & & & 1 & \multirow{3}{*}{5} \\
\hline & $\mathrm{b}$ & & & & & & & & & & & & & & \\
\hline & C & & & 1 & & & & & 1 & & & & & & \\
\hline \multirow{3}{*}{ Lucano } & $a$ & & & 2 & & & & 1 & & & & & 1 & 1 & \multirow{3}{*}{5} \\
\hline & b & & & & & & & & & & & & & & \\
\hline & C & & & & & & & & & & & & & & \\
\hline \multirow{3}{*}{ Marcial } & $\mathrm{a}$ & & & & & & & & & & & & 2 & & \multirow{3}{*}{5} \\
\hline & b & 1 & 1 & & & & & & & & & & & & \\
\hline & c & & & & & & & & 1 & & & & & & \\
\hline \multirow{3}{*}{ Flavio Josefo } & $\mathrm{a}$ & & & & & & & & & & 1 & & 1 & & \multirow{3}{*}{5} \\
\hline & $\mathrm{b}$ & & & & & & & 1 & & & & & & & \\
\hline & c & & & & & & & & 2 & & & & & & \\
\hline \multirow{3}{*}{ Estrabón } & $\mathrm{a}$ & & & & 1 & & & & & & & & & & \multirow{3}{*}{4} \\
\hline & $\mathrm{b}$ & & & & & & & & & & & 1 & & & \\
\hline & c & & & & & & 1 & & & & & 1 & & & \\
\hline \multirow{3}{*}{ Séneca } & a & & & & & & & & & & 1 & & 2 & & \multirow{3}{*}{4} \\
\hline & b & & & & & & & & & & & & & & \\
\hline & c & & & & & & & & & & & & & 1 & \\
\hline \multirow{3}{*}{ Galeno } & a & & & & & 1 & & 1 & & & & & & & \multirow{3}{*}{3} \\
\hline & $\mathrm{b}$ & & & & & & & & & & & & & & \\
\hline & C & & & & & & & 1 & & & & & & & \\
\hline
\end{tabular}




\begin{tabular}{|c|c|c|c|c|c|c|c|c|c|c|c|c|c|c|c|}
\hline Autor & & P1 & P2 & P3 & P4 & P5 & P6 & P7 & P8 & P9 & $\begin{array}{l}P \\
10\end{array}$ & $\begin{array}{c}P \\
11\end{array}$ & $\begin{array}{c}P \\
13\end{array}$ & $\begin{array}{l}P \\
14\end{array}$ & $\begin{array}{l}\text { Total } \\
\text { citas }\end{array}$ \\
\hline \multirow{3}{*}{$\begin{array}{c}\text { Quinto } \\
\text { Curcio } \\
\text { Rufo }\end{array}$} & a & & & & & & & & & & & & & & \multirow{3}{*}{2} \\
\hline & b & & & & & & & & & & & & & & \\
\hline & C & & 1 & & & 1 & & & & & & & & & \\
\hline \multirow{3}{*}{ Plutarco } & $\mathrm{a}$ & & & 2 & & & & & & & & & & & \multirow{3}{*}{2} \\
\hline & b & & & & & & & & & & & & & & \\
\hline & c & & & & & & & & & & & & & & \\
\hline \multirow{3}{*}{$\begin{array}{l}\text { Heráclides } \\
\text { Póntico }\end{array}$} & $\mathrm{a}$ & & & & & & 2 & & & & & & & & \multirow{3}{*}{2} \\
\hline & b & & & & & & & & & & & & & & \\
\hline & $\mathrm{C}$ & & & & & & & & & & & & & & \\
\hline \multirow{3}{*}{ Aulo Gelio } & $\mathrm{a}$ & & & & & & & & & & & & & & \multirow{3}{*}{2} \\
\hline & b & & & & & & & & & & & & & & \\
\hline & $\mathrm{c}$ & & 1 & & & & & 1 & & & & & & & \\
\hline \multirow{3}{*}{ Varrón } & $\mathrm{a}$ & & & & & & & & 1 & & & & & & \multirow{3}{*}{2} \\
\hline & b & & 1 & & & & & & & & & & & & \\
\hline & C & & & & & & & & & & & & & & \\
\hline \multirow{3}{*}{$\begin{array}{l}\text { Lactancio } \\
\text { Firmiano }\end{array}$} & $\mathrm{a}$ & & & & & & & & & & & & & & \multirow{3}{*}{2} \\
\hline & b & & & & & & & & & & & & & & \\
\hline & C & & & & & & 1 & & & & & & & 1 & \\
\hline \multirow{3}{*}{ Píndaro } & $\mathrm{a}$ & & 1 & & & & & & 1 & & & & & & \multirow{3}{*}{2} \\
\hline & b & & & & & & & & & & & & & & \\
\hline & C & & & & & & & & & & & & & & \\
\hline \multirow{3}{*}{ Terencio } & a & & & & & & & & & & & & 1 & & \multirow{3}{*}{2} \\
\hline & b & & & & & & & & & & & & & & \\
\hline & C & & & & & & & & 1 & & & & & & \\
\hline \multirow{3}{*}{ Demócrito } & a & 1 & & & & & & & & & & & & & \multirow{3}{*}{1} \\
\hline & b & & & & & & & & & & & & & & \\
\hline & c & & & & & & & & & & & & & & \\
\hline
\end{tabular}




\begin{tabular}{|c|c|c|c|c|c|c|c|c|c|c|c|c|c|c|c|}
\hline Autor & & P1 & P2 & P3 & P4 & P5 & P6 & P7 & P8 & P9 & $\begin{array}{c}\mathrm{P} \\
10\end{array}$ & $\begin{array}{c}P \\
11\end{array}$ & $\begin{array}{c}\mathrm{P} \\
13\end{array}$ & $\begin{array}{c}\mathrm{P} \\
14\end{array}$ & $\begin{array}{l}\text { Total } \\
\text { citas }\end{array}$ \\
\hline \multirow{3}{*}{$\begin{array}{l}\text { Valerio } \\
\text { Máximo }\end{array}$} & $\mathrm{a}$ & & & & & & & & & & & & & & \multirow{3}{*}{1} \\
\hline & b & & 1 & & & & & & & & & & & & \\
\hline & $\mathrm{c}$ & & & & & & & & & & & & & & \\
\hline \multirow{3}{*}{ Juvenal } & $\mathrm{a}$ & & & & & & & & & & & & & & \multirow{3}{*}{1} \\
\hline & $b$ & & & & & & & & & & & & & & \\
\hline & $\mathrm{c}$ & & 1 & & & & & & & & & & & & \\
\hline \multirow{3}{*}{ Calpurnio } & $\mathrm{a}$ & & & 1 & & & & & & & & & & & \multirow{3}{*}{1} \\
\hline & $b$ & & & & & & & & & & & & & & \\
\hline & c & & & & & & & & & & & & & & \\
\hline \multirow{3}{*}{ Cleantes } & $\mathrm{a}$ & & & & & & 1 & & & & & & & & \multirow{3}{*}{1} \\
\hline & $b$ & & & & & & & & & & & & & & \\
\hline & c & & & & & & & & & & & & & & \\
\hline \multirow{3}{*}{ Suetonio } & $a$ & & & & & & & 1 & & & & & & & \multirow{3}{*}{1} \\
\hline & b & & & & & & & & & & & & & & \\
\hline & $\mathrm{c}$ & & & & & & & & & & & & & & \\
\hline \multirow{3}{*}{ Hesíodo } & $a$ & & & & & & & & 1 & & & & & & \multirow{3}{*}{1} \\
\hline & b & & & & & & & & & & & & & & \\
\hline & c & & & & & & & & & & & & & & \\
\hline \multirow{3}{*}{ Plauto } & $\mathrm{a}$ & & & & & & & & & & & & & & \multirow{3}{*}{1} \\
\hline & b & & & & & & & & 1 & & & & & & \\
\hline & c & & & & & & & & & & & & & & \\
\hline \multirow{3}{*}{ Quintiliano } & $\mathrm{a}$ & & & & & & & & & & & & & & \multirow{3}{*}{1} \\
\hline & b & & & & & & & & & & & & & & \\
\hline & c & & & & & & & & 1 & & & & & & \\
\hline \multirow{3}{*}{ Arato } & $\mathrm{a}$ & & & & & & & & & & 1 & & & & \multirow{3}{*}{1} \\
\hline & $\mathrm{b}$ & & & & & & & & & & & & & & \\
\hline & c & & & & & & & & & & & & & & \\
\hline
\end{tabular}




\begin{tabular}{|c|c|c|c|c|c|c|c|c|c|c|c|c|c|c|c|}
\hline Autor & & P1 & P2 & P3 & P4 & P5 & P6 & P7 & P8 & P9 & $\begin{array}{c}\mathrm{P} \\
10\end{array}$ & $\begin{array}{l}P \\
11\end{array}$ & $\begin{array}{c}P \\
13\end{array}$ & $\begin{array}{l}P \\
14\end{array}$ & $\begin{array}{l}\text { Total } \\
\text { citas }\end{array}$ \\
\hline \multirow{3}{*}{ Menandro } & $\mathrm{a}$ & & & & & & & & & & 1 & & & & \multirow{3}{*}{1} \\
\hline & b & & & & & & & & & & & & & & \\
\hline & c & & & & & & & & & & & & & & \\
\hline \multirow{3}{*}{ Epiménides } & $\mathrm{a}$ & & & & & & & & & & 1 & & & & \multirow{3}{*}{1} \\
\hline & b & & & & & & & & & & & & & & \\
\hline & c & & & & & & & & & & & & & & \\
\hline \multirow{3}{*}{$\begin{array}{l}\text { Plinio } \\
\text { «el Joven» }\end{array}$} & $\mathrm{a}$ & & & & & & & & & & & & & & \multirow{3}{*}{1} \\
\hline & b & & & & & & & & & & & & & & \\
\hline & c & & & & & & & & & & & & & 1 & \\
\hline \multirow{3}{*}{ Resumen } & a & 3 & 6 & 9 & 1 & 5 & 7 & 5 & 6 & 0 & 10 & 1 & 9 & 6 & 68 \\
\hline & $b$ & 2 & 8 & 1 & 1 & 7 & 1 & 2 & 2 & 0 & 2 & 3 & 0 & 0 & 29 \\
\hline & c & 3 & 6 & 7 & 2 & 4 & 5 & 6 & 10 & 3 & 2 & 3 & 0 & 3 & 54 \\
\hline Total & & 8 & 20 & 17 & 4 & 16 & 13 & 13 & 18 & 3 & 14 & 7 & 9 & 9 & 151 \\
\hline
\end{tabular}

En el Panegírico por la poesía se citan 36 autoridades (22 latinos y 14 griegos) desde los siglos viII a. C. hasta el siglo v. En los siguientes cuadros se contienen las obras citadas, distribuidas por materias. Aparece en primer lugar el número de citas correspondientes a cada autor, con el título de la obra en el caso en que este aparezca; entre paréntesis figura el número del período y el número de citas que contiene el mismo. 


\section{Autores griegos}

\begin{tabular}{|c|c|c|c|c|c|}
\hline Materia & Autores & $\begin{array}{c}\text { Sólo } \\
\text { cita autor }\end{array}$ & $\begin{array}{c}\text { Cita } \\
\text { autor y obra }\end{array}$ & $\begin{array}{c}\text { Localiza } \\
\text { la cita }\end{array}$ & $\begin{array}{c}\text { Cita del autor } \\
\text { sin localizar }\end{array}$ \\
\hline \multirow{5}{*}{ Filosofía } & Aristóteles & $\begin{array}{c}5(3: 1,6: 3 \\
7: 1)\end{array}$ & & $\begin{array}{c}\text { Ética } \\
\text { nicomáquea, } 1 \\
(4: 1) \\
\text { Metafísica, } 1 \\
(6: 1) \\
\text { Retórica, } 1(6: 1) \\
\text { Física, } 1(4: 1) \\
\text { Del alma, } 1(4: 1)\end{array}$ & \\
\hline & Platón & & Fedro,1 (3:1) & $\begin{array}{c}\text { República, } 1 \\
(8: 1) \\
\text { Leyes,2 (2:1, } \\
3: 1)\end{array}$ & $2(1: 1,3: 1)$ \\
\hline & Demócrito & $1(1: 1)$ & & & \\
\hline & $\begin{array}{l}\text { Heráclides } \\
\text { Póntico }\end{array}$ & $2(6: 2)$ & & & \\
\hline & Cleantes & $1(6: 1)$ & & & \\
\hline \multirow{5}{*}{ Poetas } & Homero & $\mid \begin{array}{c}9(2: 3,3: 1 \\
5: 1,6: 1 \\
8: 1,10: 1 \\
14: 1)\end{array}$ & $\begin{array}{c}\text { Odisea, } 2(1: 1 \\
3: 1) \\
\text { Iliada, } 1(5: 1)\end{array}$ & & \\
\hline & Hesíodo & $1(8: 1)$ & & & \\
\hline & Píndaro & $2(2: 1,8: 1)$ & & & \\
\hline & Arato & $1(10: 1)$ & & & \\
\hline & Epimenides & $1(10: 1)$ & & & \\
\hline Geografía & Estrabón & $1(4: 1)$ & & $\begin{array}{c}\text { Geografía (sin } \\
\text { citar la obra), } 3 \\
(6: 1,11: 2)\end{array}$ & \\
\hline $\begin{array}{c}\text { Historiografía } \\
\text { y biografía }\end{array}$ & Plutarco & & & & $2(3: 2)$ \\
\hline Medicina & Galeno & $2(7: 1,5: 1)$ & & $\begin{array}{c}\text { De sanitate } \\
\text { tuenda, } 1(7: 1)\end{array}$ & \\
\hline Comedia & Menandro & $1(10: 1)$ & & & \\
\hline
\end{tabular}




\begin{tabular}{|c|c|c|c|c|c|c|}
\hline Materia & Autores & $\begin{array}{c}\text { Sólo } \\
\text { cita autor }\end{array}$ & $\begin{array}{c}\text { Cita } \\
\text { autor y obra }\end{array}$ & \multicolumn{2}{c|}{$\begin{array}{c}\text { Localiza } \\
\text { la cita }\end{array}$} & \multicolumn{2}{|c|}{$\begin{array}{c}\text { Cita del autor } \\
\text { sin localizar }\end{array}$} \\
\hline Total & 14 autores & 27 & 4 & 12 & 4 & 47 citas \\
\hline$\%$ & 100 & 57.44 & 8.51 & 25.53 & 8.51 & 100 \\
\hline
\end{tabular}

Autores latinos

\begin{tabular}{|c|c|c|c|c|c|}
\hline Materia & Autores & $\begin{array}{c}\text { Sólo } \\
\text { cita autor }\end{array}$ & $\begin{array}{c}\text { Cita autor } \\
\text { y obra }\end{array}$ & $\begin{array}{l}\text { Localiza } \\
\text { la cita }\end{array}$ & $\begin{array}{l}\text { Cita del autor } \\
\text { sin localizar } \\
\text { o localización } \\
\text { incompleta }\end{array}$ \\
\hline \multirow[t]{3}{*}{ Oratoria } & Cicerón & $\begin{array}{c}2(6: 1, \\
14: 1)\end{array}$ & $\begin{array}{c}\text { De oratore, } 1 \\
(1: 1) \\
\text { Pro Archia } \\
\text { poeta, } 1(2: 1) \\
\text { Pro Sextio } \\
\text { Roscio, } 1(5: 1)\end{array}$ & $\begin{array}{c}\text { De divinatione, } \\
2(1: 1,9: 1) \\
\text { Orator, } 1(1: 1) \\
\text { Pro Archia } \\
\text { poeta, } 5(2: 2, \\
3: 2,5: 1) \\
\text { Tusculanae, } 2 \\
\text { (7:1, 11:1) } \\
\text { De officiis, } 1 \\
(11: 1)\end{array}$ & \\
\hline & Quintiliano & & & $\begin{array}{c}\text { Institutio } \\
\text { oratoria (sin } \\
\text { citar la obra), } 1 \\
(8: 1)\end{array}$ & \\
\hline & $\begin{array}{l}\text { Plinio el } \\
\text { Joven }\end{array}$ & & $\begin{array}{c}\text { Panegírico a } \\
\text { Trajano, } 1 \\
(14: 1)\end{array}$ & & \\
\hline Gramáticos & Varrón & $1(8: 1)$ & & $\begin{array}{c}\text { De imaginibus, } \\
1(2: 1)\end{array}$ & \\
\hline Filosofía & Séneca & $\begin{array}{c}3(10: 1, \\
13: 2)\end{array}$ & & De ira, $1(14: 1)$ & \\
\hline
\end{tabular}




\begin{tabular}{|c|c|c|c|c|c|}
\hline Materia & Autores & $\begin{array}{c}\text { Sólo } \\
\text { cita autor }\end{array}$ & $\begin{array}{c}\text { Cita autor } \\
\text { y obra }\end{array}$ & $\begin{array}{l}\text { Localiza } \\
\text { la cita }\end{array}$ & $\begin{array}{l}\text { Cita del autor } \\
\text { sin localizar } \\
\text { o localización } \\
\text { incompleta }\end{array}$ \\
\hline \multirow{7}{*}{ Poetas } & Virgilio & $\begin{array}{c}7(2: 1, \\
10: 3,13: 2 \\
14: 1)\end{array}$ & $\begin{array}{c}\text { Eneida, } 2(2: 1 \\
7: 1)\end{array}$ & $\begin{array}{c}\text { Eneida, } 4(5: 4) \\
\text { Bucólicas, } 1 \\
(8: 1) \\
\text { Geórgicas, } 1 \\
(8: 1)\end{array}$ & \\
\hline & Horacio & $\begin{array}{c}5(5: 1,8: 2, \\
10: 1,11: 1 \\
\text { como los } \\
\text { Horacios })\end{array}$ & $\begin{array}{c}\text { Arte Poética, } \\
5(3: 1,5: 3, \\
11: 1)\end{array}$ & Odas, 1 (8:1) & $\begin{array}{c}\text { Odas, } 1 \text { (11:1). } \\
\text { Se transcriben } \\
\text { versos de } \\
\text { "Carm. I", sin } \\
\text { indicar que son } \\
\text { de Horacio }\end{array}$ \\
\hline & Ovidio & $\begin{array}{c}3(1: 1,3: 1 \\
14: 1)\end{array}$ & $\begin{array}{l}\text { Arte Poética } \\
\text { (por Ars } \\
\text { Amandi), } 1 \\
(3: 1)\end{array}$ & $1(8: 1)$ & \\
\hline & Lucano & $\begin{array}{c}4(3: 2,7: 1 \\
13: 1)\end{array}$ & $\begin{array}{c}\text { Farsalia, } 1 \\
(14: 1)\end{array}$ & & \\
\hline & Marcial & $\begin{array}{c}3(13: 2 \\
2: 1)\end{array}$ & & $\begin{array}{l}\text { Epigramas, } 2 \\
(1: 1 ; 8: 1, \text { sin } \\
\text { citar la obra })\end{array}$ & \\
\hline & Juvenal & & & Sátiras, $1(2: 1)$ & \\
\hline & Calpurnio & $1(3: 1)$ & & & \\
\hline
\end{tabular}




\begin{tabular}{|c|c|c|c|c|c|}
\hline Materia & Autores & $\begin{array}{c}\text { Sólo } \\
\text { cita autor }\end{array}$ & $\begin{array}{l}\text { Cita autor } \\
\text { y obra }\end{array}$ & $\begin{array}{l}\text { Localiza } \\
\text { la cita }\end{array}$ & $\begin{array}{l}\text { Cita del autor } \\
\text { sin localizar } \\
\text { o localización } \\
\text { incompleta }\end{array}$ \\
\hline \multirow{5}{*}{$\begin{array}{c}\text { Historiografia } \\
\text { y biografía }\end{array}$} & Tácito & $\begin{array}{c}3(5: 2 \\
14: 1)\end{array}$ & $\begin{array}{c}\text { De moribus } \\
\text { germanibus, } 1 \\
(6: 1)\end{array}$ & $\begin{array}{c}\text { Anales, } 8 \text { (2:1, } \\
3: 1,7: 2,9: 1, \\
10: 3) \\
\text { De moribus } \\
\text { germanibus, } 1 \\
(7: 1) \\
\text { Historias, } 1 \\
(10: 1)\end{array}$ & \\
\hline & $\begin{array}{c}\text { Quinto } \\
\text { Curcio Rufo }\end{array}$ & & $\begin{array}{c}\text { Historia de } \\
\text { Alejandro } \\
\text { Magno, } 2(2: 1, \\
5: 1)\end{array}$ & & \\
\hline & $\begin{array}{l}\text { Valerio } \\
\text { Máximo }\end{array}$ & & & $\begin{array}{c}\text { Hechos y dichos } \\
\text { memorables (sin } \\
\text { citar obra), } 1 \\
(2: 1)\end{array}$ & \\
\hline & Flavio Josefo & $\begin{array}{c}2(10: 1 ; \\
13: 1)\end{array}$ & & $\begin{array}{l}\text { Antigüedades } \\
\text { judías, } 3(7: 1, \\
8: 2 \text {, en una } \\
\text { ocasión sin citar } \\
\text { la obra) }\end{array}$ & \\
\hline & Suetonio & $1(7: 1)$ & & & \\
\hline $\begin{array}{l}\text { Científicos, } \\
\text { naturalistas }\end{array}$ & Plinio & & & $\begin{array}{c}\text { Historia } \\
\text { natural (sin } \\
\text { citar la obra), } \\
6(2: 3,7: 1, \\
8: 1,9: 1)\end{array}$ & \\
\hline \multirow{2}{*}{ Comedia } & Plauto & & $\begin{array}{c}\text { Asinaria, } 1 \\
(8: 1)\end{array}$ & & \\
\hline & Terencio & $1(13: 1)$ & & $\begin{array}{c}\text { Eunuco, } 1 \\
(8: 1)\end{array}$ & \\
\hline Miscelánea & $\begin{array}{l}\text { Aulo } \\
\text { Gelio }\end{array}$ & & & $\begin{array}{c}\text { Noctes atticae } \\
\text { (sin citar la } \\
\text { obra), } 2(2: 1, \\
7: 1)\end{array}$ & \\
\hline
\end{tabular}




\begin{tabular}{|c|c|c|c|c|c|c|}
\hline Materia & Autores & $\begin{array}{c}\text { Sólo } \\
\text { cita autor } \\
\text { Apologética }\end{array}$ & $\begin{array}{c}\text { Lactancio } \\
\text { Firmiano }\end{array}$ & $\begin{array}{c}\text { Cita autor } \\
\text { Localiza } \\
\text { la cita }\end{array}$ & $\begin{array}{c}\text { Cita del autor } \\
\text { sin localizar } \\
\text { o localización } \\
\text { incompleta }\end{array}$ \\
\hline Total & 22 autores & 36 & 17 & $\begin{array}{c}\text { Divinae } \\
\text { Institutiones, } \\
2 \\
(6: 1,14: 1)\end{array}$ & & 104 \\
\hline$\%$ & 100 & 34.95 & 16.50 & 48.54 & 0.97 & 100 \\
\hline $\begin{array}{c}\text { Total } \\
\text { autores } \\
\text { griegos y } \\
\text { latinos }\end{array}$ & 36 & 63 & 21 & 62 & 5 & 151 \\
\hline \% & 100 & 41.72 & 13.90 & 41.05 & 3.31 & 100 \\
\hline
\end{tabular}




\section{Bibliografía}

Álvarez Martí Aguilar, Manuel, «Notas sobre el papel de Estrabón en la historiografía española, del Renacimiento a la Ilustración», Estrabón e "Iberia»: nuevas perspectivas de estudio, coord. Gonzalo Cruz Andreotti, Málaga, Universidad, 1999, 31-62.

Antón MarTínez, Beatriz, El tacitismo en el siglo XVII en España: el proceso «receptio», Valladolid, Universidad de Valladolid, 1992.

Arcaz Pozo, Juan Luis, «Hurtado de Mendoza, traductor de Ovidio: Amores I 5 y 8", Actas del VIII Congreso Español de Estudios Clásicos, vol. III, 1994, 349-356.

—, Las obras amatorias de Ovidio en los manuscritos de España, Madrid, Universidad Complutense de Madrid, 1992.

Arce Menéndez, Ángeles, «Suárez de Figueroa y su versión de La Piazza universale de Garzoni: entre texto y paratexto», Cuadernos de filología italiana, 15 (2008), 93-124.

BLÜHER, Karl Alfred, Séneca en España: investigaciones sobre la recepción de Séneca en España desde el siglo XIII hasta el siglo XVII, ed. Juan Conde, Madrid, Gredos, 1983.

Boccaccio, Giovanni, Genealogía de los dioses paganos, ed. Ma Consuelo Álvarez y Rosa Ma Iglesias, Madrid, Editora Nacional, 1983.

Cacho Casal, Rodrigo, "Marca Tulia se llamaba una dueña: la vieja consejera en la poesía burlesca del Siglo de Oro», Criticón, 100 (2007), 71-90.

Cerda, Francis, «La transmisión de la exégesis en la oratoria sagrada del siglo XVII (El caso del Panegírico funeral del rey Felipe III por Fray Hortensio Paravicino)», Criticón, 102 (2008), 37-53.

Chevalier, Máxime, Lectura y lectores en la España de los siglos XVI y XVII, Madrid, Turner, 1976.

Clavería, Carlos, «Quintiliano, Virgilio y Horacio no son negocio. La imprenta española en el siglo XVI», Criticón, 65 (1995), 5-15.

Conde Parrado, Pedro, y Javier García Rodríguez, «Ravisio Téxtor entre Cervantes y Lope de Vega: una hipótesis de interpretación y una coda teórica», Tonos. Revista electrónica de estudios filológicos. Editores Antonio Miguel Bañón Hernández, Juana Castaño Ruiz, José María Jiménez Cano y Miguel Ángel Olmedo Chica, 14-11-12, < http://www.um.es/tonosdigital/znum4/ estudios/ravisio.htm >.

Curtius, Ernst Robert, Literatura europea y Edad Media latina, trad. Margit Frenk Alatorre y Antonio Alatorre, vol. II, México, Fondo de Cultura Económica, 1955 (2a reimp. 1976).

Elliot, J. H., El Conde-Duque de Olivares. El politico de una época de decadencia, trad. Teófilo de Lozoya, Barcelona, Grijalbo Mondadori, 1998.

Erasmo de Rotterdam, Desiderio, El ciceroniano (o sobre el mejor estilo), ed. Manuel Mañas Núñez, Madrid, Akal, 2009. 
FERnÁNDEZ López, Jorge, “"Hablar por Cicerón”: retórica española vs. retórica latina en el siglo XVI", Actas del V Congreso Internacional de la Asociación Internacional Siglo de Oro: Münster 1999, coord. Christoph Strosetski, Madrid, Iberoamericana; Frankfurt am Main: Vervuert, 2001, 514-522.

Fernández Madrid, Ma Teresa, y Manuel Gómez Lorente , «El convento de Nuestra Señora de la Salceda. Análisis histórico y simbólico», Wad-alHayara: Revista de estudios de Guadalajara, 19 (1992), 431-444.

Fernando García, Laura, "Nuevos tiempos para lo clásico: la recepción de la tradición cultural de la antigüedad en la Universidad Complutense cisneriana», Tradición clásica y Universidad, ed. Francisco L. Lisi Bereterbide, Madrid, Dykinson, 2010, 51-65.

García Cárcel, Ricardo, Las culturas del Siglo de Oro, Madrid, Historia 16, 1999.

García Galiano, Ángel, La imitación poética en el Renacimiento, Kassel, Reichenberger, 1992.

-, "Las polémicas sobre Cicerón en el renacimiento europeo», Escritura e imagen, 6 (2010), 241-266.

Garzoni, Tomaso, Piazza universale di tutte le professioni del mondo, Venetia, ad instantia di Roberto Meglietti, 1605.

GIL, Luis, Los antiguos y la «inspiración» poética, Madrid, Guadarrama, 1967.

Gil Fernández, Luis, "La enseñanza universitaria del griego y su valoración social», Tradición clásica y Universidad, ed. Francisco L. Lisi Bereterbide, Madrid, Dykinson, 2010, 51-29-49.

Gilson, Étienne, Dante et Beatrice, Paris, Librairie Philosophique J. Vrin, 1974.

GonzÁlez Barrera, Julián, «Lope de Vega y los «librotes de lugares comunes»: su lectura particular de Ravisio Téxtor», Anuario Lope de Vega, 13 (2007), 51-71.

González de Mendoza, Pedro, Historia del Monte Celia de Nuestra Señora de la Salceda, Granada, por Iuan Muñoz, 1616.

Guerrero, Gustavo, Teorías de la lírica, México, Fondo de Cultura Económica, 1998.

Guzmán, Juan de, Primera parte de la Rhetorica de Ioan de Guzman...: diuidida en catorze Combites de Oradores: donde se trata el modo que se deue guardar en saber seguir un concepto por sus partes, en qualquiera platica, razonamiento, $o$ sermon, en el genero deliueratiuo, de todo lo qual se pone la theorica y pratica..., Alcala de Henares, en casa de Ioan Yñiguez de Lequerica, 1589.

Hernández Miguel, Luis Alfonso, La tradición clásica. La transmisión de las literaturas griega y latina antiguas y su recepción en las vernáculas occidentales, Madrid, Liceus, 2008.

Herrero Llorente, Víctor-José, «Tácito y el vulgo», Estudios clásicos, tomo 5, 31 (1960), 407-421.

—, «Lucano en la literatura hispano-latina», Emerita, 27 (1959), pp. 19-52.

Highet, Gilbert, La tradición clásica: influencias griegas y romanas en la literatura 
occidental, vol. II, trad. Antonio Alatorre, México, Fondo de Cultura Económica, 1978.

Horacio Flaco, Quinto, Odas, trad. Alfonso Cuatrecasas, Madrid, Espasa Calpe, 2005.

Infantes, Víctor, «De Officinas y Polyantheas: los diccionarios secretos del Siglo de Oro», Homenaje a Eugenio Asensio, ed. Luisa López Grigera y Agustín Redondo, Madrid, Gredos, 1988, 245-257.

La renovación poética del Renacimiento al Barroco, ed. Begońa López Bueno, Madrid, Síntesis, 2006.

Lange, Joseph, Novissima Polyanthea in libros XX. dispertita: Opus praeclarum, suavissimis floribus celebriorum sententiarum, cum Graecarum, tum Latinarum refertum / Primum quidem a Dominico Nano Mirabellio, Bartholomaeo Amantio, Francisco Tortio, ex Auctoribus tam sacris, quam profanis, vetustioribus et recentioribus collectum... Studio et opera Josephi Langii, Francofvrti, Haeredum Lazari Zetzneri, 1617.

LÁzaro Carreter, Fernando, «Imitación compuesta y diseño retórico en la Oda a Juan de Grial», Fray Luis de León: [Actas de la I Academia Literaria Renacentista], dir. Víctor García de la Concha, Universidad de Salamanca, 1981, 193-223.

Lida de Malkiel, María Rosa, La tradición clásica en España, Barcelona, Ariel, 1975.

López PozA, Sagrario, «Florilegios, polyanteas, repertorios de sentencias y lugares comunes. Aproximación bibliográfica», Criticón, 49 (1990), 61-76.

—, "La difusión y recepción de la "Antología griega» en el Siglo de Oro», En torno al canon: aproximaciones y estrategias. VII Encuentro Internacional sobre Poesía del Siglo de Oro, ed. Begoña López Bueno, Grupo PASO, Universidad de Sevilla, 2005.

Lucano, La Farsalia, ed. Víctor-José Herrero Llorente, Madrid, Consejo Superior de Investigaciones Científicas, 1996 ( $2^{\mathrm{a}} \mathrm{ed}$.).

Marías, Fernando, «El verdadero Sacro Monte, de Granada a La Salceda: Don Pedro González de Mendoza, Obispo de Sigüenza, y el Monte Celia», Anuario del Departamento de Historia y Teoría del Arte, Universidad Autónoma de Madrid, vol. IV, 1992, 133-144.

Mexía, Pedro, Silva de varia lección, ed. Antonio Castro, Madrid, Cátedra, 1989.

Moreno Garrido, Antonio, "El grabado en Granada durante el siglo XVII», Cuadernos de Arte de la Universidad de Granada, vol. 13, n. 26-28, 1976.

NúŃEz GonzÁlez, Juan María, El ciceronianismo en España, Universidad de Valladolid, 1993.

PINedA, Victoria, La imitación como arte literario en el siglo XVI español. (Con una edición y traducción del diálogo "De imitatio" de Sebastián Fox Morcillo), Diputación Provincial de Sevilla, 1994.

Plutarco, Moralia, trad. Concepción Morales Otal y José García López, Madrid, Gredos, 2000. 
Porqueras Mayo, Alberto, La teoría poética en el Manierismo y Barroco españoles, Barcelona, Puvill, 1989.

Reulos, Michel, «Aristole Dans les collages du xvie siècle», xvie Colloque Internactional de Tours. Platon et Aristole à la Renaissance, Paris, Librairie Philosophique J. Vrin, 145-154.

Rico García, José Manuel, «La perfecta idea de la altísima poesía». Las ideas estéticas de Juan de Jáuregui, Diputación de Sevilla, 2001.

Roвortello, Francesco, In librum Aristotelis De arte poetica explicationes..., Florentiae, in Officina Laurentii Torrentini, 1548.

Rodríguez Ayllón, Jesús Alejandro, Un hito en el nacimiento de la Historia de la literatura española: los Orígenes de la poesia castellana (1754) de Luis José Velázquez, Málaga, Fundación Unicaja, 2010.

Roger, Jacques, «Aristole et les anatomistes padouans», XVIe Colloque Internactional de Tours. Platon et Aristole à la Renaissance, Paris, Librairie Philosophique J. Vrin, 217-224.

Ruiz Pérez, Pedro, «Los repertorios latinos en la edición de textos áureos. La Officina poética de Ravisio Textor", La edición de textos. Actas del I Congreso Internacional de Hispanistas del Siglo de Oro, eds. Pablo Jauralde, Dolores Noguera y Alfonso Rey, London, Tamesis Books Limited, 1990, 431-440.

Schevill, Rudolph, Ovid and the Renascence in Spain, Hildesheim, Georg Olms, 1971.

Schmitт, Charles Bernard., «L'introduction de la philosophie platonicienne dans l'enseignement des Universités à la Renaissance ", Xvie Colloque Internactional de Tours. Platon et Aristole à la Renaissance, Paris, Librairie Philosophique J. Vrin, 1976, 93-104.

—, Aristotle and the Renaissance, trad. Silvia Manso, Universidad de León, 1983.

Schwartz, Lía, «La poesía grecolatina en el siglo xvi: las traducciones de los clásicos», El canon poético en el siglo XVI, ed. Begoña López Bueno, Grupo PASO, Universidad de Sevilla, 2008, 19-45.

Simón DíAz, José, "Autores extranjeros traducidos al castellano en impresos publicados durante los siglo Xv-XvII», Cuadernos Bibliográficos, 40 (1980), 23-52.

Sullà, Eric, «El debate sobre el canon literario», El canon literario, ed. Eric Sullà, Madrid, Arco/Libros, 1998, 11-34.

TÁcıтo, Cayo Cornelio, Tacito español ilustrado con aforismos [y traducida] por don Baltasar Alamos de Barrientos, Madrid, Luis Sa[n]chez, a su costa y de Iuan Hafrey, 1614.

Trías, Eugenio, El artista y la ciudad, Barcelona, Anagrama, 1997.

Tubau, Xabier, Una polémica literaria: Lope de Vega y Diego de Colmenares, Madrid, Iberoamericana; Frankfurt am Main, Vervuert, 2007.

VAlla, Lorenzo, De linguae latinae elegantia, trad. Santiago López Moreda, Cáceres, Universidad de Extremadura, 1999.

Velazquez de Velasco, Luis José, Epistolario del Marqués de Valdeflores a Agustín 
Montiano y Luyando, durante el viaje científico que realizó por España [Manuscrito], 1752-1755.

—, Luis José, Origenes de la poesía castellana, Málaga, en la Oficina de Francisco Martínez de Aguilar, 1754.

[Vera y Mendoza, Fernando de], Panegyrico por la poesia, Montilla, por Manuel de Payua, 1627. 